\title{
Volcanic Clouds from the 1999 Eruption of Shishaldin Volcano: Comparison of Satellite and Seismic Observations
}

David J. Schneider ${ }^{1}$ and Glenn Thompson ${ }^{2,3}$

${ }^{\prime}$ Alaska Volcano Observatory, U.S. Geological Survey

4200 University Drive, Anchorage, AK 99508

djschneider@usgs.gov; (907)786-7037; fax 786-7425

${ }^{2}$ Alaska Volcano Observatory, Geophysical Institute, University of Alaska Fairbanks, Fairbanks, AK 99775

${ }^{3}$ Now at Montserrat Volcano Observatory, Mongo Hill, Montserrat, West Indies 


\begin{abstract}
The main ash-producing phase of the 1999 eruption of Shishaldin Volcano, Alaska, occurred on April 19 and ejected ash as high as $16 \mathrm{~km}$ asl. High levels of tremor persisted for more than 18 hours, but ash production probably lasted less than 4 hours. The total erupted volume of the April 19 event was estimated to be at least $2.0 \times 10^{7} \mathrm{~m}^{3}$ DRE. Upper level winds transported mainly sulfur dioxide to the north above $10 \mathrm{~km}$ altitude, and mainly ash to the south below that level. The relationship between seismicity and ash cloud production changed following the April 19 event. Episodes of strong amplitude tremor from April 21 to 24 were associated with strong strombolian activity, but very little ash was produced that could be detected in satellite images. On several occasions in late May, extensive ash plumes were detected in AVHRR and GOES images, but seismic levels during these times of ash production remained at low-levels. Satellite data suggest that the ash produced during the May events contained more fine particles than that produced by the April 19 event.
\end{abstract}




\section{Introduction}

Shishaldin Volcano $\left(54^{\circ} 45^{\prime} \mathrm{N}, 163^{\circ} 58^{\prime} \mathrm{W}\right)$ is located near the center of Unimak Island, approximately $1100 \mathrm{~km} \mathrm{SW}$ of Anchorage, Alaska. The symmetrical cone-shaped stratovolcano is predominantly basaltic (Fournelle, 1988), and with a summit elevation of $2857 \mathrm{~m}$, it is the highest peak in the Aleutian Islands. It is also one of the most active volcanoes in Alaska, with at least 27 eruptions since 1775, and major explosive eruptions occurring in 1830 and 1932 (Miller et al., 1998). Most other reported activity was strombolian ash and steam eruptions. Prior to the 1999 eruption, the most recent activity was a poorly documented short-lived eruption of steam and ash that may have reached as high as $10 \mathrm{~km}$ asl (above sea level) on December 23, 1995 (Neal and McGimsey, 1997).

This paper outlines how satellite and seismic data were used in a complimentary fashion during the 1999 eruption of Shishaldin Volcano to evaluate the intensity of activity and the resulting hazard to aircraft. Satellite-derived cloud height estimates were used to estimate eruption rate and volume. Our analysis indicates that seismic tremor amplitude is positively correlated with ash production (as observed by satellite images) during the initial (and largest) ash producing eruption on April 19, 1999, but as the eruption progressed, this relationship was not maintained.

\section{Satellite Monitoring}

The Alaska Volcano Observatory (AVO) uses satellite image data from three polar-orbiting and one geostationary satellite to monitor volcanic activity in Alaska (Table 1). Mid-infrared images (3.5-4.0 $\mu \mathrm{m}$ wavelength) from the AVHRR and GOES sensors are used to detect and measure volcanic thermal anomalies (Dean et al., 1998; Harris et al., 2000) and volcanic ash clouds are detected and tracked using thermal infrared (10-12 
$\mu \mathrm{m}$ wavelength) data (Schneider et al., 1995; Schneider et al., 2000). AVHRR and GOES image data are calibrated (using percent albedo for visible channels and brightness temperature for infrared channels) and registered to map projections that cover the volcanoes. Processed AVHRR and GOES data are available for analysis within 5 and 20 minutes of reception, respectively. Available images are analyzed twice each day, and many times

per day during a crisis, typically as soon as they are received (every 15 minutes for GOES). Analysis of thermal anomaly information during the 1999 eruption of Shishaldin played an important role in AVO's monitoring strategy (Dehn et al., this volume).

In this study, the eruption cloud height was estimated from satellite images using two methods: (1) comparison of cloud brightness temperature to a temperature profile of the atmosphere (derived from radiosonde data collected at Cold Bay, $100 \mathrm{~km} \mathrm{NE}$ of the volcano) and (2) cloud displacement. The cloud displacement technique works well when observing a high-latitude eruption from a geostationary satellite such as GOES. The GOES satellite collects images of Alaskan volcanoes at low-elevation angles, approximately $15^{\circ}$ to $23^{\circ}$ above the horizon. As an eruption cloud rises, it becomes progressively displaced from the vent towards the northwest (for Alaska). If the curvature of the earth is ignored, the cloud height $(\mathrm{h})$ can be estimated by:

$\mathrm{h}=\mathrm{d} \tan \theta$

Where $\mathrm{d}$ is measured cloud displacement and $\theta$ is the satellite elevation angle $\left(22.5^{\circ}\right.$ for Shishaldin).

\section{Seismic Monitoring}

A network of 12 seismometers was installed on Unimak Island during the summers of 1997-98 to monitor activity at 4 historically active volcanoes in this region (Is- 
anotski, Shishaldin, Fisher Caldera, and Westdahl). Data from these instruments are relayed to the AVO seismic laboratories in real time via radio, telephone, microwave and Internet networks. The seismic signals are displayed on drum recorders and digitized for use in locating earthquakes. The seismicity associated with volcanic tremor is analyzed with plots of reduced displacement and spectral content.

Reduced displacement $\left(D_{r}\right)$ is a method of normalizing volcanic tremor recorded at various distances from a volcano to a common scale, and is an absolute measure of volcanic tremor amplitude. It is equal to the maximum sustained root-mean-square ground displacement multiplied by a correction factor for geometric spreading. The correction factor depends on how much of the tremor signals are body or surface waves ( $A k i$ and Koyanagi, 1981; Fehler, 1983). Both formulations assume the tremor is recorded in the far field of a point source. No corrections are made for path or site effects.

Two methods exist for calculating $D_{r}$. The simplest is to measure the maximum sustained root-mean-square signal from the displacement seismogram and multiply it by the appropriate correction factor. An equivalent method for digital data is as follows: (1) calculate the amplitude spectrum of the displacement seismogram; (2) apply the correction factor; (3) divide the maximum spectral peak by $\sqrt{2}$.

At the AVO the maximum $D_{r}$ in a 10-minute data sample is computed for 5 stations at 15 volcanoes and displayed on the World-Wide Web in near real-time (Benoit et al., 1998). 1024 samples are used for the FFT and the tremor is assumed to consist entirely of surface waves. Wind data from the National Weather Service are also plotted, since, in the absence of tremor $D_{r}$ correlates with wind. 


\section{Eruption: Summary of Precursory Activity}

Seismic unrest began in June 1998 with a series of small low frequency earthquakes located 10-20 km west of the summit. On February 9, 1999 a thermal anomaly was first observed in a satellite image, accompanied by a vigorous steam emission, visible from the village of Cold Bay $(100 \mathrm{~km} \mathrm{NE})$. Very low-level tremor was identified a week later on February 18. Re-examination of seismic records showed that tremor likely began in mid-January, but was not identified at the time due to the low level of the activity that was frequently obscured by storms and high winds. On March 4, a shallow M 5.2 earthquake occurred about $14 \mathrm{~km}$ west of Shishaldin followed by several hundred aftershocks. An M 4.5 event occurred in this same area on April 12. These earthquakes were likely related to the intrusion of magma beneath the volcano (Moran et al., this volume). Mid-infrared satellite data (AVHRR channel 3) indicated that the source of the thermal anomaly was likely rising in the summit crater beginning in early March (Dehn et al., this volume). Several episodes of increased tremor amplitude occurred on April 7-8, and on April 12. The persistent thermal anomaly was observed in satellite images, but there was no evidence of volcanic plumes. Thompson et al., (this volume) give more detail on the tremor associated with the 1999 eruption.

\section{Satellite Observations and Seismicity: April 17 to 24, 1999}

A summary of the satellite observations and seismic data from April 17 to 24 is shown in Figure 1. In this figure, reduced displacement is plotted from a representative seismic station (SSLW, located $10 \mathrm{~km} \mathrm{~W}$ of the summit), and minor steam and ash plumes refer to those that extended for less than $50 \mathrm{~km}$ from the vent at altitudes of less than $7.5 \mathrm{~km}$ asl (above sea level). Tremor began to increase steadily on April 17 as indi- 
cated by increasing $D_{r}$ levels (Fig. 1). A low-level strombolian eruption was observed on April 18 around 0030 UTC (ADT=UTC-8) by AVO staff flying in the area (McGimsey et al., 1999), but activity was confined to the summit crater and no plumes were observed.

The main ash-producing phase of the eruption was marked by an abrupt and large increase in tremor amplitude that started on April 19 at approximately 1930 UTC, and lasted for approximately 20 minutes before starting to decline. A GOES satellite image (visible channel data) collected at 1915 UTC showed the start of the eruption as a small point source cloud rising above the meteorological cloud deck that had an estimated height of ca. $3 \mathrm{~km}$ asl. Subsequent images show the development of the eruption cloud from 1945 to 2230 UTC (Fig. 2a-f). By 1930 UTC the cloud height was estimated at ca. 5 $\mathrm{km}$ asl (summit elevation $2.85 \mathrm{~km}$ ) using the cloud displacement technique (Fig. 3).

Initially the cloud appeared bright (high albedo), suggesting high water content in the eruption cloud (Fig. 2a), and was elongated from the vent towards the SSE. By 2000 UTC the cloud had evolved to a circular shape, indicative of the umbrella region of an eruption column (Fig 2b). The estimated maximum cloud height had increased to ca. 16 $\mathrm{km}$ asl and the cloud albedo had decreased, suggesting that the eruption cloud had become more ash-rich. Subsequent images showed bi-directional cloud movement. Comparison of this movement to radiosonde wind data collected at Cold Bay (100 km NE) on April 19 at 0000 UTC indicates that the portion of the cloud below $10 \mathrm{~km}$ moved towards the SSE, and the portion of the cloud above $10 \mathrm{~km}$ moved towards the NNW. By 2130 UTC (Fig. 2e) the eruption cloud had begun to lose its circular shape, suggesting that the intensity of the eruption had decreased. The estimated height of the eruption cloud continued to decrease from $14.7 \mathrm{~km}$ asl at 2130 UTC to $5.9 \mathrm{~km}$ asl at 2330 UTC (Fig. 3). By 
0100 UTC on April 20, only a minor steam and ash plume was being emitted at an altitude of ca. $5 \mathrm{~km}$ asl.

Although a significant ash cloud was generated by the main phase of the eruption, the volcanic cloud did not have a negative brightness temperature difference $(10.5 \mu \mathrm{m}-$ $11.5 \mu \mathrm{m})$ indicative of airborne ash (Prata, 1989). Mapping of fall deposits from the April 19 event show that the main mass of ash was deposited on the south flank of Shishaldin, with very little ash deposited north of the vent (Stelling et al., this volume). This pattern of ash dispersion is consistent with winds at altitudes of less than $10 \mathrm{~km}$ asl. However the sulfur dioxide cloud, as detected by the TOMS satellite, was detected north of the volcano on April 20 (G. Bluth, pers. comm., 1999), which is consistent with winds above $10 \mathrm{~km}$ asl. A stratospheric aerosol layer was detected at a location hundreds of kilometers to the north at an altitude of ca. $17 \mathrm{~km}$ asl on April 23 by the POAM III satellite, and persisted through early May, 1999 (Bevilacqua et al., 1999). These observations document the separation of volcanic ash and sulfur dioxide clouds, which has been noted in previous eruptions that have reached the stratosphere (Schneider et al., 1999; Constantine et al., 2000; Mayberry et al., 2000).

Tremor amplitude fluctuated following the ash-producing phase of the eruption, with three periods of strong tremor recorded at levels close to, and at times exceeding, those recorded during the main ash-producing phase (Fig. 1). These fluctuations in tremor amplitude correlate with abrupt changes in tremor frequency, suggesting two distinct tremor sources that may be linked to different flow regimes within the conduit. Further, periods of strong explosions as recorded on a pressure sensor correlate with the high tremor amplitudes (Thompson et al., this volume). No ash plumes were observed in satel- 
lite images during these times. The high levels of tremor continued until $\Lambda$ pril 20 at 1200 UTC, when it decreased abruptly to very low levels.

Tremor began increasing once again on April 21 at 0000 UTC, and by 1800 UTC had reached $D_{r}$ levels near those recorded during the ash-producing eruption on April 19. The tremor intensity continued to increase through April 22 until reaching a peak on April 23 at 0600 UTC that was far in excess of those recorded on April 19. Intense thermal activity was observed in both AVHRR and GOES images throughout this time period. The GOES sensor has a much larger spatial resolution than AVHRR (ca. $64 \mathrm{~km}^{2}$ versus $1 \mathrm{~km}^{2}$, respectively), and can only observe activity occurring outside of the crater due to its low viewing angle at high latitude. Thus the observations of thermal anomalics in GOES images presumably correspond to the most intense periods of lava fountaining. Steam and ash plumes were observed in AVHRR and GOES images during this time, with the largest one observed April 23 at 0525 UTC extending to the south for ca. $50 \mathrm{~km}$ at a height of ca.7 km asl. Tremor decreased on April 23 around 1200 UTC.

\section{Eruption Rate and Volume Estimates}

There is a strong dependence of eruption cloud height on thermal energy release, as noted by Morton et al. (1956), which in turn is dependent upon volume eruption rate (Wilson et al., 1978). The satellite-derived eruption cloud height estimates (Fig. 3) of the ash producing eruption on April 19 were used to calculate eruption rate and eruption volume for this event using these models and the results are shown in Figure 4, along with $D_{r}$ levels from station SSLW. Where cloud altitude estimates were made from two sources (e.g. 1930 to 2000 UTC), an average value was used to calculate the discharge rate. The peak eruption rate was ca. $4.2 \times 10^{3} \mathrm{~m}^{3} / \mathrm{s}$, calculated from the cloud height in the image from 
2000 UTC, decreased slightly to $3.3 \times 10^{3} \mathrm{~m}^{3} / \mathrm{s}$ from 2015 UTC through 2100 UTC, and then declined. The integrated eruption volume was $2.0 \times 10^{7} \mathrm{~m}^{3}$ (DRE), which is in very good agreement with the value of $1.4 \times 10^{7} \mathrm{~m}^{3}$ (DRE) reported by Stelling et al. (1999) on the basis of extrapolated fall deposit mapping.

Comparisons of eruption rate and $D_{r}$ show that the peak eruption rate (2000 UTC) lags slightly behind the peak tremor at the start of the eruption (1950 UTC), but this due to the fact that it takes time for the cloud produced by an eruption to reach its maximum height. In general, there is good agreement between the eruption rate and $D_{r}$ from 1930 UTC through 2100 UTC. However, the eruption rate starts to decline after 2100 UTC at a time when $D_{r}$ levels begin to increase rapidly. High levels of tremor from 2130 through 2400 UTC correspond to progressively decreasing eruption rate. During this time strong explosions were recorded on a pressure sensor (Thompson et al., this volume), perhaps indicative of intense strombolian activity that did not produce much fine ash.

\section{Satellite Observations and Seismicity: May 25 to 27, 1999}

Seismicity decreased to very low levels $\left(<1 \mathrm{~cm}^{2} D_{r}\right)$ following the eruptive activity in late April, and the intensity of the thermal anomaly decreased. The period of relative quiescence lasted until May 19 when tremor pulses were again seen in seismic records. Another pulse occurred on May 21, and on May 24 tremor pulses became continuous and increased to $D_{r}$ levels of ca. $2 \mathrm{~cm}^{2}$ (Fig. 6). Low-level (ca. $5 \mathrm{~km}$ asl) ash plumes were detected in AVHRR and GOES images starting around 0400 UTC on May 25, and satellite data show that ash production was continuous through about 0400 UTC on May 26 (Fig 7a-c). The clouds extended for several hundreds kilometers to the south. Al- 
though continuous low-level tremor was occurring, ash production appears to have begun without any recognizable change in seismicity.

Following this period of ash production, the tremor intensity began increasing, reaching a peak around 1400 UTC on May 26. Although the volcano was obscured by clouds during the start of this increase in tremor, clear conditions for a satellite image collected at 1500 UTC showed only a minor steam plume. Another low-level ash plume was observed in GOES and AVHRR images starting at 1700 UTC on May 26. This continuous plume continued to grow (Fig. $7 \mathrm{~d}-\mathrm{f}$ ), ultimately reaching a length of at least $500 \mathrm{~km}$ before detaching from the vent around 0600 UTC on May 27. Shortly after the plume detached, seismicity peaked again, but no plume was observed in the GOES images. Unlike the ash cloud produced by the April 19 event, those produced from May 25 to 27 had brightness temperature differences indicative of volcanic ash. This was the last significant activity observed in satellite images.

\section{Discussion}

A relationship between $D_{r}$, Volcano Explosivity Index, and ash column height has been proposed by McNutt (1994) as a means of assessing the hazards from airborne volcanic ash. A critical $D_{r}$ level of $10 \mathrm{~cm}^{2}$ has been suggested as indicating a 60 to 80 percent chance that an ash cloud from an explosive eruption has reached more than $8 \mathrm{~km}$ as! altitude, a level at which many jet aircraft fly. There were 6 periods of $D_{r}$ in excess of 10 $\mathrm{cm}^{2}$ from April 19 to 24, but only the first one was definitely associated with an ash cloud to levels that could have affected aircraft at cruise altitude (ca. $8 \mathrm{~km}$ asl). The highest $D_{r}$ levels recorded during the entire 1999 eruption peaked on April 23 at ca. 0600 UTC, and were associated with a relatively small ash and steam cloud that rose near the base of 
flight levels at ca.7 km asl. Given the intensity of the tremor, the uncertainty in cloud altitude, and the potential for a more significant eruption, this event was of concern to AVO and to the aviation industry. As noted previously by McNutt (1994) significant changes in vent size, vent geometry, and tremor source (among others) can occur over time that will affect the relationship between $D_{r}$ and ash column height. Analysis of tremor associated with the April 19 event suggests systematic changes in tremor source (Thompson et al., this volume). Extensive low-level ash plumes extending downwind for hundreds of kilometers were produced on May 25-27. Although low-level tremor was continuous during this time, the ash plumes were erupted without any significant change in tremor levels. These clouds were not hazardous to aircraft at cruise level, but were of concern to general aviation in the region and to aircraft on approach and departure from Cold Bay, an important alternate airport for aircraft flying North Pacific routes.

Although these observations show that the interpretation of $D_{r}$ plots for evaluating hazards to aviation can be improved with the analysis of near real-time satellite data, this may be difficult to do at the start of an eruption due to the time lag between image collection, data transfer, processing, and interpretation of the satellite data. The first image that clearly showed a large eruption cloud was not collected until 1945 UTC on April 19 (Fig. 2b), and was not available for interpretation until after 2000 UTC, at which time the eruption had been in progress for ca. 30 minutes. In situations when satellite data is not immediately available, warnings should be issued on the basis of seismicity and knowledge of prior explosive characteristics of the volcano.

Although the April 19 eruption produced an ash cloud that reached the stratosphere, at no time during its evolution did it exhibit a brightness temperature difference 
$(10 \mu \mathrm{m}-12 \mu \mathrm{m})$ indicative of volcanic ash. In general, volcanic clouds consisting of silicate particles are characterized by negative brightness temperature differences (BTD) provided they are 1) partially transparent, 2) underlain by a much warmer surface, and 3) predominantly fine grained ash (ca. 0.1 to $15 \mu \mathrm{m}$ radius) (Prata, 1989; Wen and Rose, 1994). Clouds imaged shortly after eruption may be opaque owing to high concentrations of ash and/or abundant entrained water, and may not exhibit negative BTDs indicative of ash. However, as the cloud disperses and becomes partially transparent, the BTD is able to discriminate the ash (Schneider et al., 1995). The coarse-grained nature of the Shishaldin fall deposit may help to explain why the ash cloud was not detectable in GOES BTD images. The proximal fall deposit from the April 19 event consisted of very wellsorted, highly angular scoria ranging from 0.3 to $>5.0 \mathrm{~cm}$ in median diameter, with very little fine ash ( $J$. Beget, pers. comm., 2000). Thus, the eruption cloud may have been too coarse-grained to be discriminated by BTD. However, ash plumes erupted during late May were discriminated by this technique, suggesting that the clouds produced during that phase of the eruption contained more fine-grained ash.

\section{Conclusions}

Satellite and seismic data were used successfully by the AVO in a complementary manner during the 1999 eruption of Shishaldin volcano to evaluate the intensity of activity and the resulting hazard to aviation. The largest ash-producing event occurred on April 19. Although seismicity remained at very high levels of intensity for more than 18 hours during this event, significant ash production as detected in satellite images lasted for no more than 4 hours, and likely lasted for less than 2 hours. Satellite observations show that the sulfur dioxide cloud from this eruption was transported to the north at an 
altitude of at least $16 \mathrm{~km}$ and separated from the volcanic ash cloud, which was transported to the south at an altitude of less than $10 \mathrm{~km}$. Satellite-derived ash cloud height information was used to estimate the eruption volume at $2.0 \times 10^{7} \mathrm{~m}^{3}$ (DRE). A decoupling of seismicity and ash production occurred on April 19 following the main ash producing eruption, and it continued throughout April and May. Very strong tremor on April 22-23 was associated with intense strombolian activity that produced relatively minor steam and ash plumes. Extensive low-level ash plumes extending for hundreds of kilometers were produced on May 25-27. Although low-level tremor was continuous during this time, the ash plumes were erupted without any significant change in tremor levels. Interpretation of reduced displacement plots for evaluating hazards to aviation is greatly improved by availability of near real-time satellite data. Satellite data suggest that the ash produced during the May 25-27 events were finer grained than that erupted on May 19 .

\section{References}

Aki K, Koyanagi RY (1981) Deep volcanic tremor and magma ascent mechanism under Kilauea, Hawaii. J Geophys Res 86:7095-7110

Benoit J, Thompson G, Lindquist K, Hansen, R, McNutt SR (1998) Near-realtime WWW-based monitoring of Alaskan Volcanoes: The IceWeb system. EOS Trans AGU: 79:F957

Bevilacqua RM, Fromm MD, Hornstein JS, Shettle EP, Alfred J (1999) POAM III observations of the Mt. Shishaldin volcanic plume. EOS Trans $\Lambda$ GU 80:F200

Constantine EK, Bluth GJS, Rose WI (2000) TOMS and AVHRR observations of drifting volcanic clouds from the August 1991 eruptions of Cerro Hudson. In: Mouginis- 
Mark P, Crisp J, Fink J (eds) Remote Sensing of Active Volcanism. American Geophysical Union. Geophysical Monograph 116:45-63

Dean K, Servilla M, Roach A, Foster B, Engle K (1998) Satellite monitoring of remote volcanoes improves study efforts in Alaska, EOS Trans AGU 79:413, 422-423

Dehn J, Dean KG, Engle K, Izbekov (2000) Thermal precursors in satellite imagery of the 1999 eruption of Shishaldin Volcano. Bull. Volcanol., this volume.

Fehler M (1983) Observations of volcanic tremor at Mount St. Helens volcano. J Geophys Res 88:3476-3484

Fournelle JH (1988) Geology and petrology of Shishaldin Volcano: Unimak Island, Aleutian arc, Alaska, The Johns Hopkins University, unpublished Doctoral Dissertation, $507 \mathrm{p}$

Harris AJL, Flynn LP, Dean K, Wooster E, Okubo O, Mouginis-Mark P, Garbiel H, Thornber C, Rothery D, Wright R (2000) Real-time monitoring of volcanic hot spots with satellites. In: Mouginis-Mark P, Crisp J, Fink J (eds) Remote Sensing of Active Volcanism. American Geophysical Union. Geophysical Monograph 116:XX-XX

Mayberry GC, Rose WI, and Bluth GJS (2000) Dynamics of the volcanic and meteorological clouds produced by the December 26, 1997 eruption of Soufriere Hills volcano, Montserrat, W.I. In: Druitt T, Blake S (eds) Special Publication of the Geological Society of London, The 1995-99 eruptions of Soufriere Hills volcano, Montserrat

McGimsey RG, Schneider DJ, Neal CA, Roach, AL (1999) Use of FLIR observations during eruption response at two Alaskan volcanoes. EOS Trans AGU 80:F1146

McNutt, SR (1994) Volcanic tremor amplitude correlated with eruption explosivity and its potential use in determining ash hazards to aviation. In: Casadevall TJ (ed) Vol- 
canic Ash and Aviation Safety: Proceedings of the First International Symposium on Volcanic Ash and Aviation Safety. USGS Bulletin 2047:377-385

Miller TP, McGimsey RG, Richter DH, Reihle JR, Nye CJ, Yount ME, Dumoulin JA (1998) Catalog of Historically Active Volcanoes of Alaska, USGS Open File Report 98$582,104 p$

Moran SC, Stihler SD, Power JA (2000) A tectonic earthquake sequence preceding the April-May eruption of Shishaldin Volcano, Alaska (2000) Bull. Volcanol., this volume.

Morton BR, Taylor G, Turner JS (1956) Turbulent gravitational convection from maintained and instantaneous sources. Proc Roy Soc Ser A 234:1-23

Neal CA, McGimsey RG (1997) 1996 volcanic activity in Alaska and Kamchatka: Summary of events and response of the Alaska Volcano Observatory, USGS Open File Report 97-433, 41p

Nye CJ, Keith TEC, Miller TP, Eichelburger JC, Dehn J, McNutt SR, Moran SC, Schneider DJ (2000) The 1999 eruptions of Shishaldin Volcano, Alaska: Remote monitoring using multiple data streams. Bull. Volcanol., this volume.

Prata AJ (1989) Infrared radiative transfer calculations for volcanic ash clouds, Geophys Res Lett, 16:1293-1296

Thompson G, McNutt SR, Tytgat G (2000) Three distinct regimes of volcanic tremor associated with eruptions of Shishaldin Volcano, Alaska, April 1999. Bull. Volcanol., this volume.

Schneider DJ, Rose WI, Kelley L (1995) Tracking of 1992 eruption clouds from Crater Peak vent of Mount Spurr volcano, Alaska, using AVHRR. In: Keith TEC (ed) The 
1992 Eruptions of Crater Peak Vent, Mount Spurr Volcano, Alaska. USGS Bulletin 2139: $27-36$

Schneider DJ, Rose WI, Coke LR, Bluth GJS, Sprod IE, Krueger AJ (1999) Early evolution of a stratospheric eruption cloud as observed with TOMS and AVHRR, J Geophys Res 104:4037-4050

Schneider DJ, Dean KG, Dehn J, Miller TP, Kirianov V Yu (2000) Monitoring and Analyses of Volcanic Activity Using Remote Sensing Data at the Alaska Volcano Observatory: Case Study for Kamchatka, Russia, December 1997. In: Mouginis-Mark P, Crisp J, Fink J (eds) Remote Sensing of Active Volcanism. American Geophysical Union. Geophysical Monograph 116:65-85

Stelling P, Beget J, Nye C, Gardner J, Devine JD, George RMM (2000) Geology and petrology of ejecta from the 1999 eruptions of Shishaldin Volcano, Alaska. Bull. Volcanol., this volume.

Wen S, Rose WI (1994) Retrieval of sizes and total masses of particles in volcanic clouds using AVHRR bands 4 and 5. J Geophys Res 99:5421-5431

Wilson L, Sparks RSJ, Huang TC Watkins ND (1978) The control of volcanic column heights by eruption energetics and dynamics, J Geophys Res 83:1829-1836 
Table 1. Operational satellite data used at AVO during the 1999 Shishaldin eruption.

\begin{tabular}{lll}
\hline Parameter & NOAA-12, -14, \&-15 & GOES-10 \\
\hline Sensor & AVHRR & Imager \\
Channels & 1: Visible $(0.6-0.7)$ & 1: Visible $(0.5-0.8)$ \\
(microns) & 2: Near-IR $(0.7-1.1)$ & 2: Mid-IR $(3.8-4.1)$ \\
& 3: Mid-IR $(3.5-3.9)$ & 3: Water Vapor \\
& 4: Thermal-IR & $(6.5-7.0)$ \\
& $(10.3-11.3)$ & $4:$ Thermal-IR \\
& $5:$ Thermal-IR & $(10.2-11.2)$ \\
& $(11.5-12.5)$ & $5:$ Thermal-IR \\
& & $(11.5-12.5)$ \\
Spatial & 1 km at nadir & Visible Channel: \\
Resolution & & $\sim 2$ km at $60^{\circ} \mathrm{N}$ \\
(km) & & All Channels: \\
& & $\sim 8$ km at $60^{\circ} \mathrm{N}$ \\
Temporal & $10-12$ images per day & 4 images per hour \\
Resolution & &
\end{tabular}


Figure 1. Plot of reduced displacement from a representative station (SSLW) and interpretations of GOES and AVHRR satellite images from April 17 to 24, 1999. "Minor steam and ash" refers to clouds that extended for less than $50 \mathrm{~km}$ from the vent at altitudes of less than $7.5 \mathrm{~km}$ asl. A thermal anomaly was observed in AVHRR images throughout the time period, but only in GOES images during the time indicated.

Figure 2. Sequence of GOES visible channel images showing the development and movement of the eruption cloud from the April 19 eruption of Shishaldin. Images were available at 15-minute increments, but only selected images are shown. Location of the volcano indicated by the crosshair. All times are on April 19, 1999, in UTC (ADT=UTC8). A) 1945 UTC. B) 2000 UTC. C) 2030 UTC. D) 2100 UTC. E) 2130 UTC. F) 2230 UTC.

Figure 3. Maximum eruption cloud altitudes determined from GOES satellite data using the cloud top temperature and cloud displacement techniques from 1915 to 2330 UTC on April 19. Altitudes are in kilometers above sea level; Shishaldin summit elevation is 2.85 $\mathrm{km}$.

Figure 4. Comparison of eruption rate (determined from cloud height information) and reduced displacement at SSLW from 1900 to 2400 UTC on April 19, 1999.

Figure 5. AVHRR mid-infrared image (channel 3) collected on April 23 at 0525 UTC. A large thermal anomaly is observed at the vent (diffuse dark region) and a steam and ash plume is seen extending south for ca. $35 \mathrm{~km}$. This image was collected during very high levels of tremor $\left(D_{r}=27 \mathrm{~cm}^{2}\right)$.

Figure 6. Plot of reduced displacement from a representative station (SSLW) and interpretations of GOES and AVHRR satellite images from May 25 to 28, 1999. The observations of ash refer to times when plumes were observed extending from the vent.

Figure 7. Sequence of AVHRR band 4-5 brightness temperature images showing the development of volcanic ash plumes (cyan-yellow-orange color) from Shishaldin Volcano. A) May 25 at 1500 UTC. B) May 25 at 1900 UTC. C) May 26 at 0350 UTC. D) May 26 at 1840 UTC. E) May 27 at 0045 UTC. F) May 27 at 0230 UTC. 


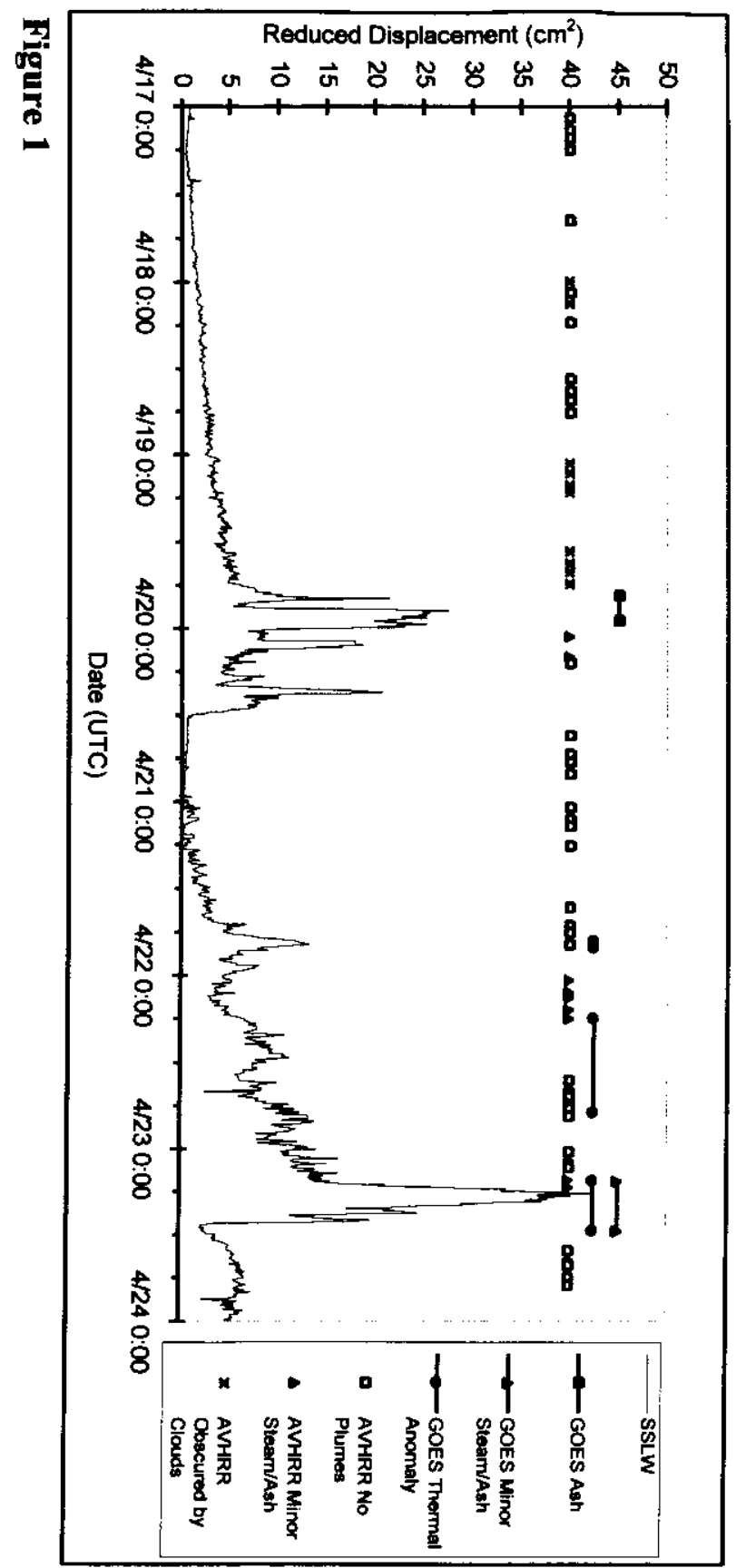



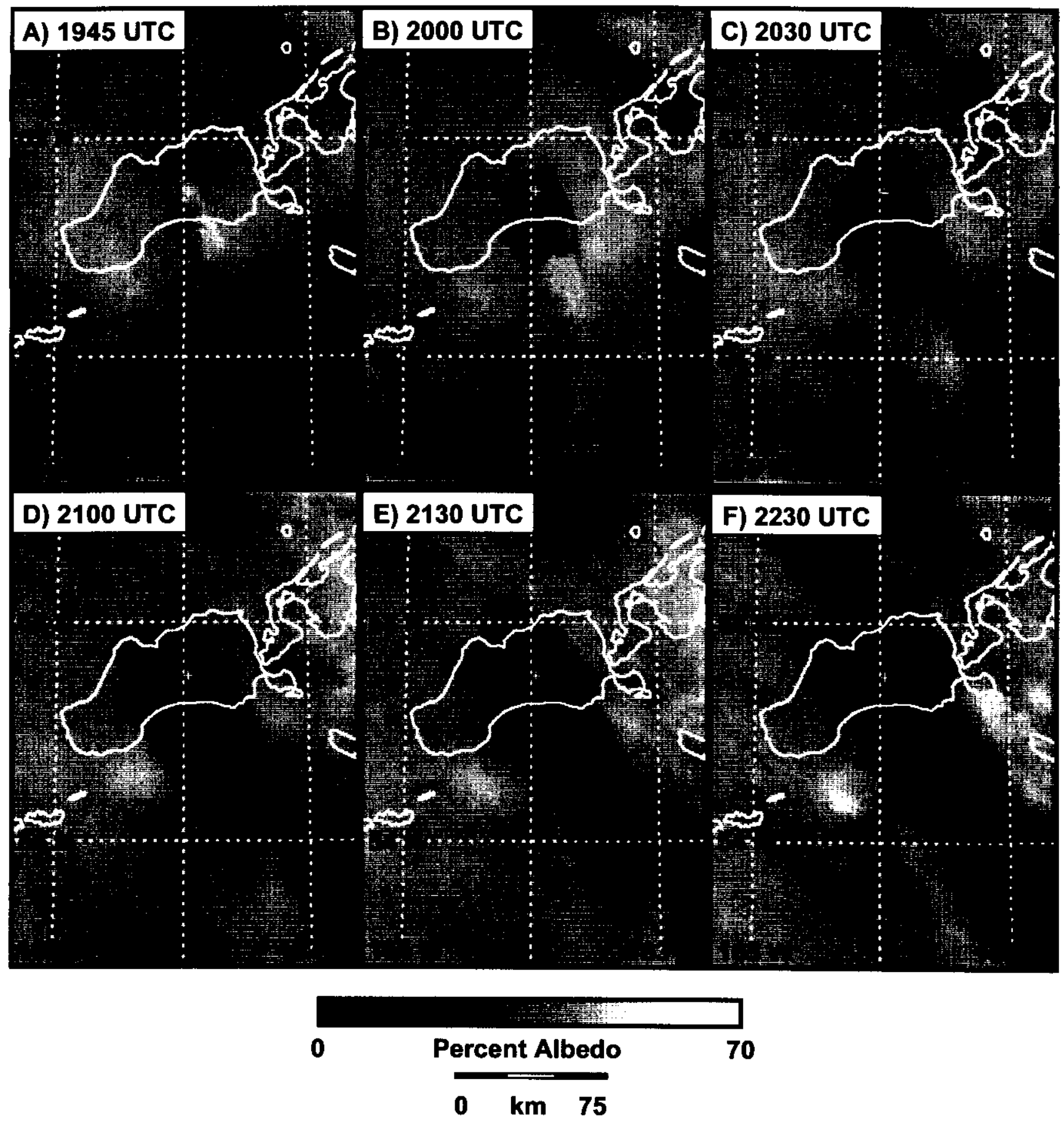

Figure 2 

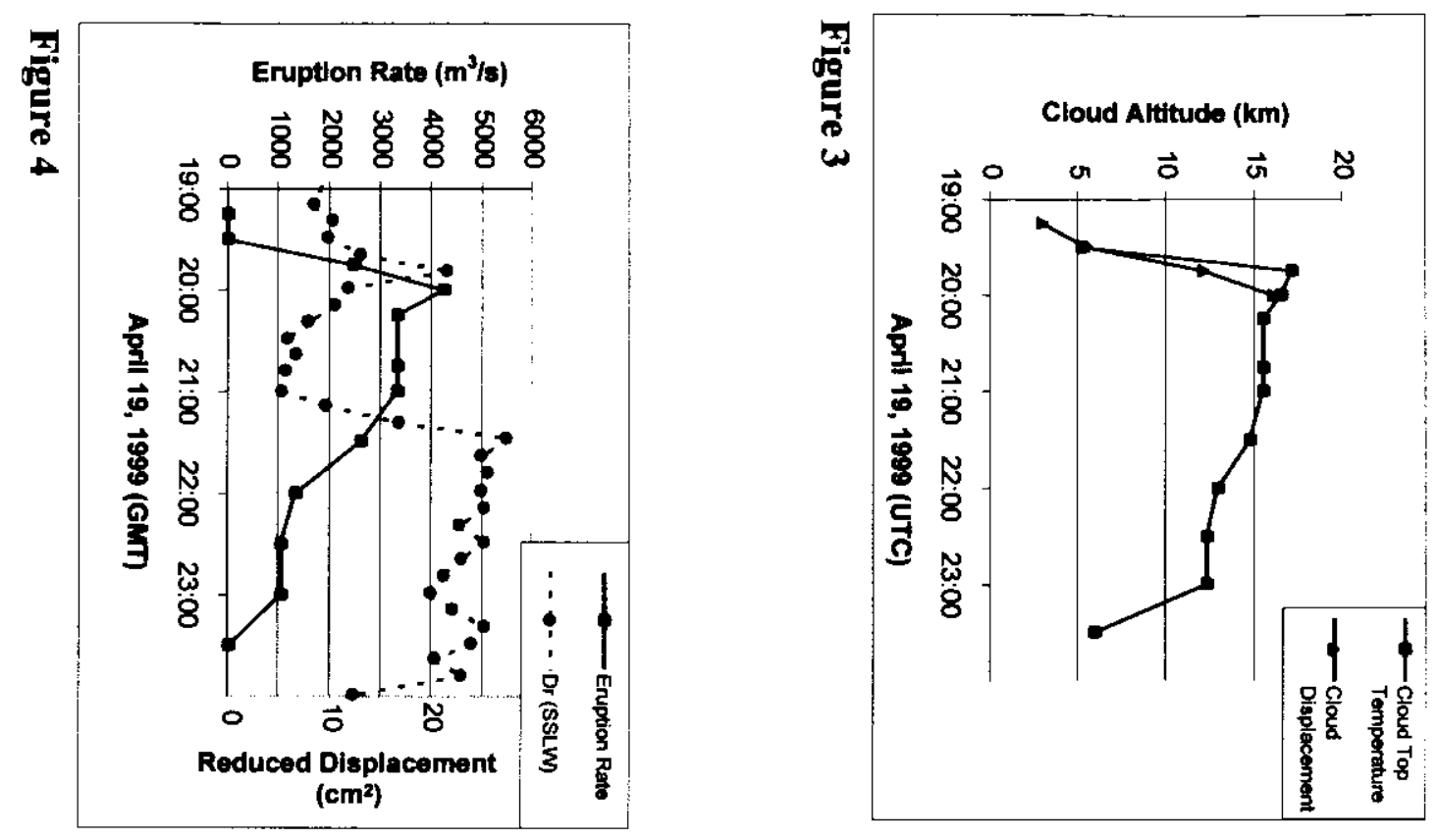


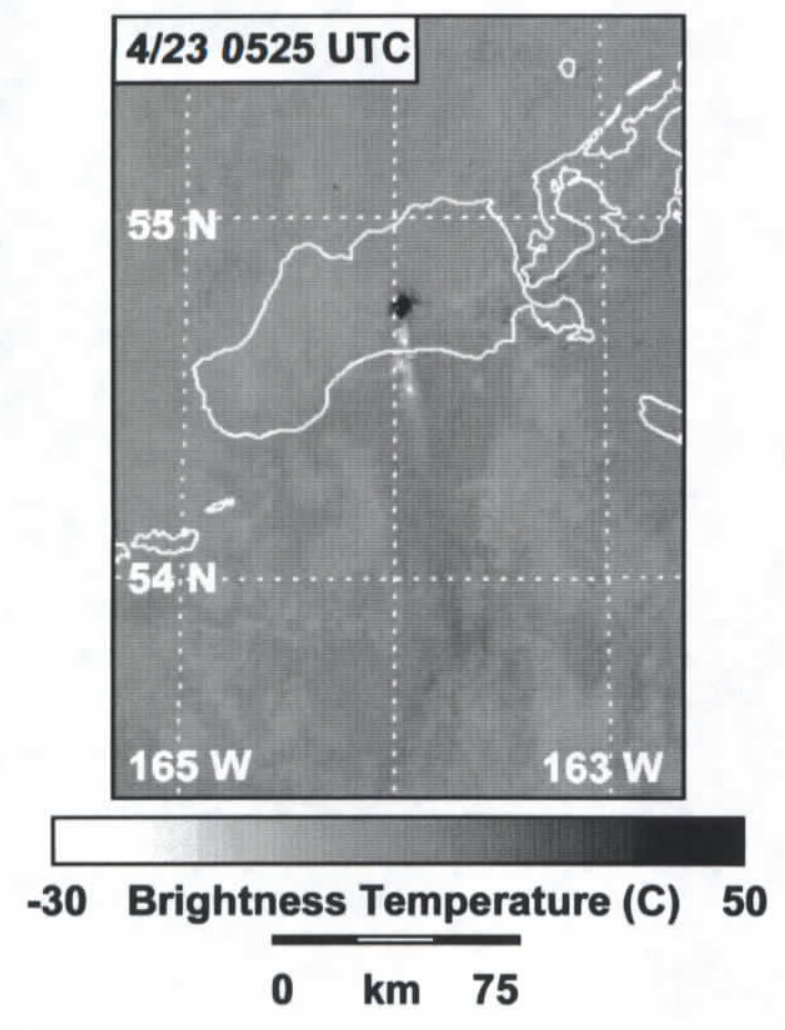

Figure 5 


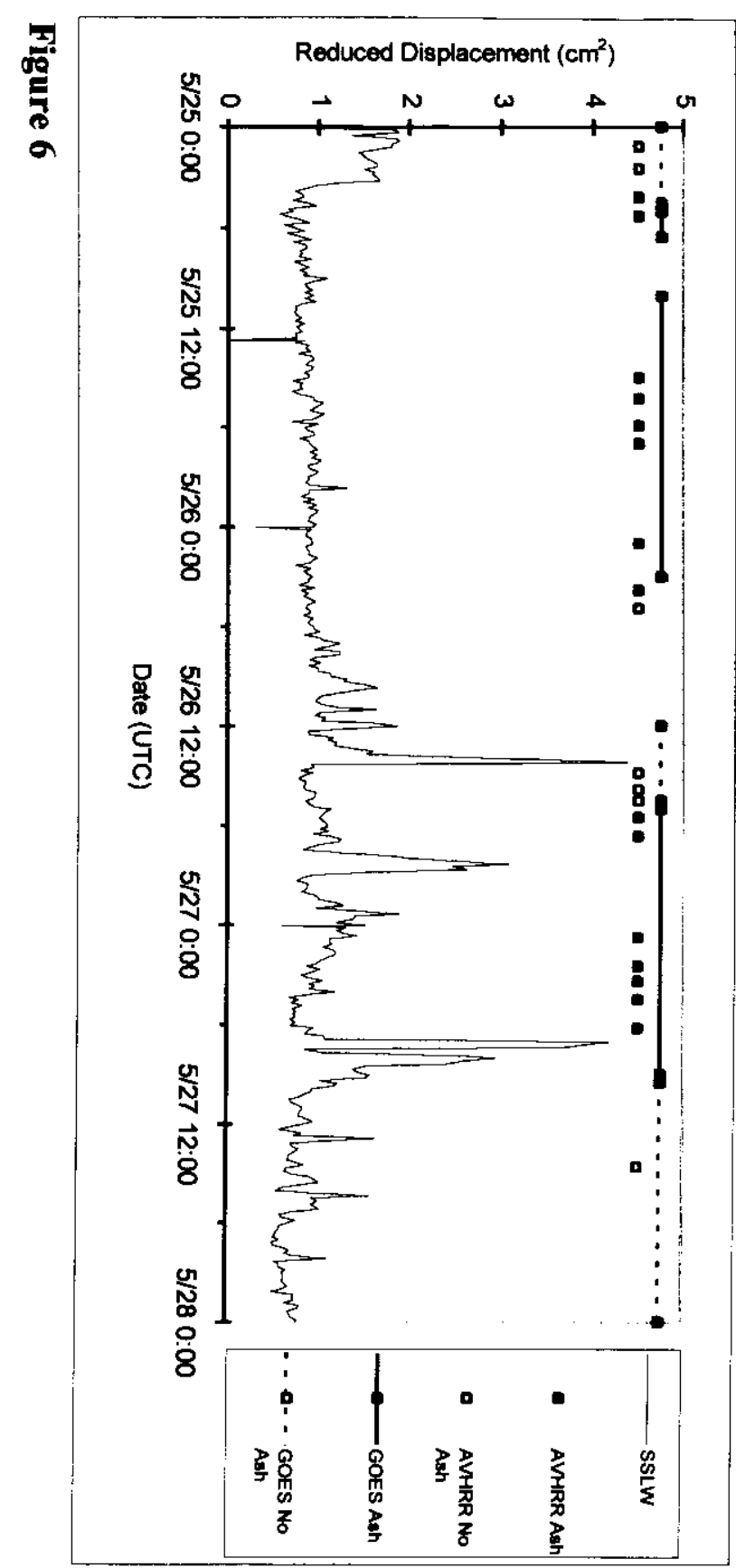



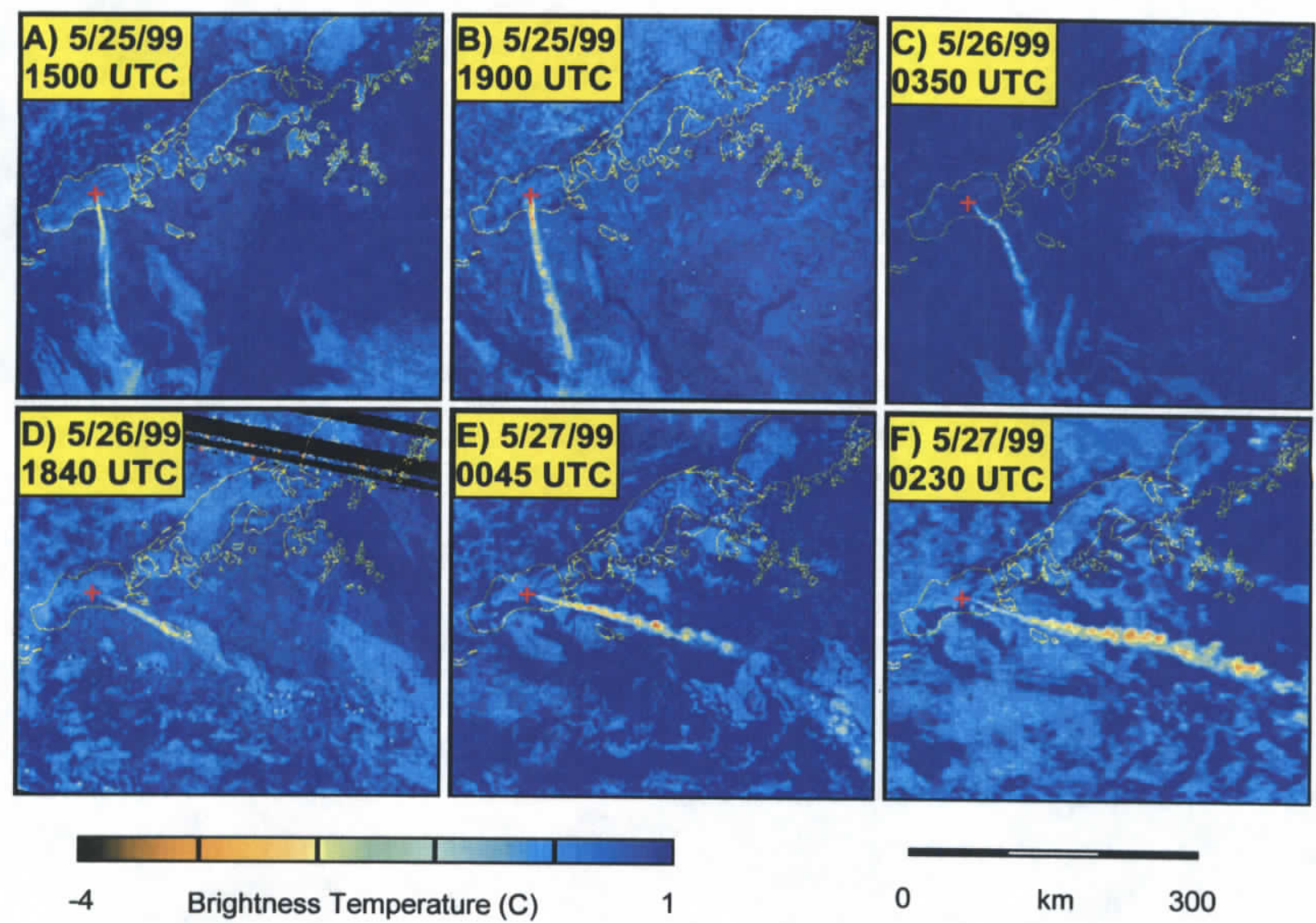

Figure 7 


\title{
Seismic monitoring of the 1999 eruptions at Shishaldin Volcano with near-real time spectrograms and reduced displacement plots on the Web.
}

\author{
Glenn Thompson, John P. Benoit, Kent Lindquist and Stephen R. McNutt
}

\section{Introduction}

Some blurb about Shishaldin background and overview chronology of 1999 eruptions.

In this paper we describe data obtained using a near-real time Web-based seismic monitoring system, loosely referred to as 'IceWeb'. The main function of this system is to produce seismic spectrograms and reduced displacement plots, these being updated every 10 minutes and linked to the Alaska Volcano Observatory's internal web page. Spectrogram data had a time resolution of $5 \mathrm{~s}$, and a frequency resolution of $0.1 \mathrm{~Hz}$, and were therefore similar but superior to SSAM data. Reduced displacement data is similar to RSAM data, but is superior because reduced displacement is a meaningful metric that can be related to ash column height and volcanic explosivity index [McNutt...].

In addition to these data, helicorder plots were also synthesized using digital data, filtered between 0.8 and $5 \mathrm{~Hz}$ in order to enhance volcanic tremor. These 'pseudohelicorder' plots were generated for all Shishaldin stations on an hourly basis and linked to AVO's internal web page. Finally an automated alarm system was also implemented which had the ability to page and email AVO seismologists when a significant increase in reduced displacement occured. However, this alarm system was unreliable because many false alarms were generated due to telemetry noise, and so it did not contribute much to the monitoring of the Shishaldin eruptions (Put this part elsewhere).

\section{Introduction}

After volcanic tremor was identified in February 1999, AVO went into 24-hour monitoring mode. Near-real-time spectrograms and reduced displacement plots, produced by the IceWeb system, were the most valuable monitoring data available to AVO during this period. On April 19th, 1999, a VEI 3 eruption occured at Shishaldin volcano sending ash up to a height of $\sim 50,000$ feet and endangering air traffic on routes between North America and Asia. This eruption was preceded by a rapid increase in reduced displacement, which enabled AVO to respond to this eruption before ash entered the air routes. 


\section{Overview of the seismic activity, January-April 1999}

Still got to write this!

\section{Tremor emerges}

During January 1999 reduced displacement at Shishaldin increased gradually and volcanic tremor was suspected. During February this tremor signal was intermittent. After early March, reduced displacement showed a linear trend until around April 5th. This increase may have been related to the March 4th earthquake.

\section{M5.2 earthquake near Shishaldin, March 4th 1999}

The March 4 earthquake produced hundreds of aftershocks, the occurence of which is shown very well on these figures. However, this aftershock sequence was unusual and much later there were several $M>4$ events, suggesting these earthquakes were in some way related to the activity at Shishaldin.

\section{Tremor hits 3cm^2 - April 1, 1999}

In the last few days of March reduced displacement rose fairly significantly. From March 28th till April 2nd three bursts of tremor can be seen, each with increasing intensity. Spectrograms for this period shows tremor, which peaks at around 1 or $2 \mathrm{~Hz}$, strengthening significantly from March 28th till April 4th.

\section{Tremor reaches $10 \mathrm{~cm}^{\wedge} 2$ - April 7, 1999}

Around 0400 UT on April 7th reduced displacement $</ a>$ rose sharply from $1-2 \mathrm{~cm}^{\wedge} 2$ up to 10 $\mathrm{cm}^{\wedge} 2$ on SSLN, but returned to low levels again by 0800 UT. However, at 1552 UT a much stronger episode of tremor began, probably coinciding with a small eruption, and persisted at high levels for several hours.

\section{April 8-13th: Tremor back at background $</$ h3 $>$}

After 1200 UT on April 8th reduced displacement $</ a>$ returned to background levels and remained between 1 and $2 \mathrm{~cm}^{\wedge} 2$ until the beginning of April 14th.

\section{Another tremor burst - April 14, 1999}

On April 14th reduced displacement rose sharply again to levels of around $5 \mathrm{~cm}^{\wedge} 2$ on SSLN. This activity persisted until the early part of April 15th, shown here on spectrograms and pseudo-helicorder plots. Strombolian activity was first observed around this time.

\section{April 16-18th: Tremor back at background}

From the beginning of April 16th, reduced displacement returned to background levels, suggesting any low-level eruptive activity had ceased. 


\section{April 19th eruption}

This eruption was preceded by a steady rise in reduced displacement for approximately 60 hours. Closer examination reveals the rise is linear rather than exponential, but that the gradient increased at 0000 UT on April 19th. Between 0000 UT and 1800 UT on April 19th, reduced displacement doubled on all stations. This gradual increase is shown well on a spectrograms.

The first indication that an significant eruption was occuring was a <rapid increase in reduced displacement. The onset of the eruption was probably 1939 UT as this corresponds to a rapid increase in seismicity seen on the following high resolution Dr plot and spectrograms.

notes - add in color code changes \& Dr vs VEI graph \& tables showing when dr hit new levels on each station + average $\&$ min

\section{Calculations of Drs and PV for various stages of the Shishaldin eruption}

Do some calculations to compare relative merits of Drs and PV as metrics of tremor amplitude (latter is calculated using decay law method). 
Date: Thu, 9 Sep 1999 12:09:05 -0800 (AKDT)

From: "Glenn Thompson (Post-Doc)" <glennegiseis.alaska.edu>

Subject: abstract submitted

To: steve@kiska.giseis.alaska.edu, doertękiska.giseis.alaska.edu, gordon@kiska.giseis.alaska.

Cc: glennekiska.giseis.alaska.edu

MIME-Version: 1.0

Content-MD5: $z$ fX49x2gqLIPmluAoy Ld6Q==

I submitted the abstract last night. Poster requested next to 'Keith et al.' (to group Shishaldin stuff together). Also requested next to 'Jolly et al.' since Art is studying reduced displacement at Montserrat (I am coauthor).

REF : 4246

PIN : 5893

Monitoring and analysis of volcanic tremor reduced displacement and spectra associated with eruptions of Shishaldin Volcano, April 1999.

Glenn Thompson, Stephen R. McNutt, Doerte Mann and Gordon R. Bower

Alaska Volcano Observatory, Geophysical Institute, University of Alaska, Fairbanks, AK 99775-7320, USA.

Tremor signals associated with Strombolian eruptions of Shishaldin Volcano on April 19 and April 23, 1999, were the strongest recorded anywhere in the Aleutian Islands by the Alaska Volcano Observatory (AVO) in its 10 year history. Throughout the 1998-1999 seismic unrest at Shishaldin, spectrograms (with a frequency resolution of $0.1 \mathrm{~Hz}$ ) and reduced displacement (Dr) plots were computed in near-real-time $(10 \mathrm{mins})$ and displayed on the World-Wide Web. These tools often gave the first warning of changes in activity, and being able to check these data remotely at any time (over the web) was invaluable. They also provided an excellent dataset for further analysis.

Analyses of Dr and spectra reveal that the eruption sequences on April 19 and April 23 followed similar patterns. Both were preceded by $\sim 2$ days of tremor which gradually intensified. A rapid increase commenced $\sim 2$ hours prior to the maximum observed $\mathrm{Dr}$ in both cases $\left(30 \mathrm{~cm}^{\wedge} 2\right.$ and $37 \mathrm{~cm}^{\wedge} 2$ respectively). Several further pulses of strong tremor (Dr $>20 \mathrm{~cm}^{\wedge} 2$ ) then occured before an abrupt reduction in tremor $\left(\mathrm{Dr}<2 \mathrm{~cm}^{\wedge} 2\right)$. Strong tremor lasted about 16 hours for April 19 and 6 hours for April 23.

However, the main phase of the April 19 eruption was characterised by a very wide-band signal associated with ash ejection to an altitude of $\sim 50000$ feet; no corresponding signal was observed in the April 23 sequence and relatively little ash was observed although a large thermal anomaly was seen in satellite data. This suggests that the main phase on April 19 corresponds to a vent clearing eruption. The dominant tremor frequency immediately after this eruption was lower than that immediately before. A significant increase in the characteristic scale length (for an exponential relation between duration and amplitude) also occured suggesting that the vent clearing eruption modified the source geometry. Strong tremor on April 23 had a higher frequency content, which is likely the result of lower gas content. Tremor was a key diagnostic for evaluating the activity of Shishaldin during its 1999 eruptions. 


\section{Shishaldin Chronology}

From: ")

From: "Seth Moran (AVO)" <smoraneamak.wr.usgs.gov>

To: "Glenn Thompson (Post-Doc)" <glennegiseis.alaska.edu>

CC: "Seth Moran (AVO)" <smoraneamak.wr.usgs.gov>

Subject: Re: Shishaldin abstract

MIME-Version: 1.0

\section{Hi Glenn,}

Sounds great, good to have another seismicity abstract in the mix! Don't want these remote smellers and geegollygists to dominate, after all... Here's the chronology I wrote back in June. Haven't done anything with it
since...

Seth

Shishaldin Eruption Chronology Note: all times are local Alaska time (Alaska Standard Time (AST) or
Alaska Daylight Time (ADT)) unless otherwise noted

Seismic unrest at Shishaldin arguably began in June of 1998, when the a series of small low-frequency events located $10-20 \mathrm{~km}$ west of the summit at depths of $0-12 \mathrm{~km}$ below sea level commenced. A key station in the AVO network was out during this time, however, resulting in very poorly constrained locations. These events continued through July, died off in mid-August, and re-commenced in late september through October. Several of the larger events in the second phase were located at shallow depths beneath the summit, which was likely a function of the fixing of the key station and the addition of several new stations to the west. Thus in earthquakes occurring that these events were likely b-type volcanic

Low frequency events died off at the end of October, although occasional events occurred in subsequent months. On February 9 a thermal anomaly was first seen on satellite imagery, and vigorous steam plumes were reported by ground observers in Cold Bay, $90 \mathrm{~km}$ NE of Shishaldin, through the next week. Identification of very low-level tremor (reduced displacement (Dr)
values of $\sim 0.5 \mathrm{~cm} 2$ ) prompted AVo to values of $\sim 0.5 \mathrm{~cm} 2$ ) prompted AVO to raise the Level of Concern Color Code (LCCC) to Yellow on February 18. Re-examination of seismic records showed that tremor actually began sometime in late January (since tremor levels were so low, conclusive identification of tremor was complicated by but seismicity remained above winds). The tremor subsequently diminished,

Early in the morning of March 4 a shallow M 5.2 earthquake occurred $\sim 14 \mathrm{~km}$ west of Shishaldin, followed in subsequent days by several hundred aftershocks located in the same area. Later that morning National weather Service observers in Col d Bay reported that the persistent steam plume had quit, and the upper summit was snow-free. On March 7 th Cold Bay observers reported hot air rising to $\sim 1500 \mathrm{~m}$ above the summit, where it condensed into steam. Cloudiness from subsequent stor ms prevented direct observations for the next several weeks, but thermal anomalies were seen intermittently on satellite data and low-level tremor continued.

On April 7 at 0800 ADT tremor abruptly increased to Dr levels of $5-7 \mathrm{~cm} 2$, causing AVO to raise the LCCC to Orange. Weather in the area was overcast with haze, preventing views of the summit area. The strong tremor declined from April 8 without significant previous levels. Tremor remained steady thermal anomaly observed in satelite imagery ph April 12, and the summit lowered the LCCC to Yellow.

On April 12 a M 4.5 earthquake with associated aftershocks occurred $\sim 12 \mathrm{~km}$ 

- W of the volcano in the same area as the M 5.2 event. Late in the evening of April 13 tremor levels increased markedly, prompting AVo to raise the LCCC to Orange on the morning of April 14. This tremor episode lasted over one day and decreased somewhat for the next three days. On April 17 AVO staff flying with the Alaska State Troopers saw a minor Strombolian eruption at $\sim 1700$ on 17 April. Incandescent blocks and spatter rose as high as $200 \mathrm{~m}$ above the vent, but at that time no lava had come over the crater rim.

On April 17 tremor levels began to increase steadily. On the morning of 18 April, observers in Cold Bay and on a ship NW of Shishaldin reported incandescence at the summit and new dark patches presumed to be snow melt running down the NW flank. A small steam plume with little or no ash developed as hot lava contacted snow at the summit. On April 19 at 1130 tremor amplitudes increased dramatically, rising to reduced displacements of over $20 \mathrm{~cm} 2$. At 1145 a commercial pilot en route to Dutch Harbor with AVO observers on board reported seeing two steam-and-ash plumes reaching at least 10,650 and 13,750 meters altitude, respectively. Satellite imagery showed a significant plume at this time, and indicated that the ash cloud was spreading both south and north of the volcano. Avo immediately raised the LCCC to Red. Seismicity levels remained elevated for several hours. Aviation warnings for 0410-1610 on Apri1 19 indicated two separate areas to avoid; one area spread $\sim 300 \mathrm{~km} \mathrm{~N}$ over an elliptically shaped zone and the other, $\sim 500 \mathrm{~km}$ S over a broadly spreading pattern that also included a lobe reaching $\sim 375 \mathrm{~km}$ NW of Shishaldin (to Chignik).

On April 20 at about 0345, seismicity abruptly and significantly declined, indicating that explosive activity had subsided. Although satellite imagery after 0650 showed a summit-crater thermal anomaly, Avo decreased the LCCC to Orange on the morning of April 20. Tremor Ievels began increasing again about 1600 on April 20th. AVO observers flying north of Shishaldin at roughly the same time reported that the cone was black with ash, with several drainages inundated by lahars extending 1-2 km beyond the base of the edifice, but saw no obvious signs of significant volcanic activity. By the morning of April 21 tremor had reached levels (Dr $\sim 10$ cm2) similar to those recorded in the hours before the April 19 eruption, causing AVO to raise the LCCC to Red. Moderate Strombolian eruptions were thought to be occurring at this time, although no ash clouds were detected in satelite imagery. Tremor levels ebbed throughout the day and were fluctuating by evening. Although lava fountains to several hundred feet above the sumnit were observed overnight and the thermal anomaly and elevated tremor persisted, no major explosive eruption occurred, and the LCCC was downgraded to Orange on the morning of April 22 .

Throughout the day of April 22 tremor gradually increased, eventually reaching $\mathrm{Dr}$ levels of over $10 \mathrm{~cm} 2$, and the summit thermal anomaly increased in size and intensity. At 1800 AVo observers flying north of the volcano reported low-level Strombolian activity reaching $\sim 150 \mathrm{~m}$ above the vent. Roughly 3 hours later at 2100 tremor levels began increasing rapidly, and the LCCC was raised to Red. Satellite data from 2020 showed a narrow plume extending $45 \mathrm{~km}$ south of the volcano, and the thermal anomaly increased to the largest size seen during this eruption sequence. Tremor levels eventually peaked at over $50 \mathrm{~cm} 2$, and then at 0200 on April 23 began rapidly declining. Satellite data from 0616 on April 23 showed a much smaller thermal anomaly consistent with low-level strombolian activity, and the LCCC was downgraded to Orange at 0800 .

In subsequent days tremor levels remained low (Dr $\sim 1 \mathrm{~cm} 2$ ), and a summit thermal anomaly smaller than those seen in the previous several days also persisted. Early in the morning of April 26 a fishing boat reported very light ash fall roughly $65 \mathrm{~km}$ southeast of the volcano. A narrow plume with a small ash component was seen in satellite imagery at this time and continued to lengthen over the course of the morning, eventually extending over $160 \mathrm{~km}$ to the northeast of the vent. Observations from ground observers in Cold Bay, pilots, and satellite imagery indicated that the 


$$
\begin{aligned}
\frac{\partial^{2}}{\partial x^{2}} \times \psi & =\frac{\partial}{\partial x}\left(\frac{\partial}{\partial x}(x \psi)\right) \\
& =\frac{\partial}{\partial x}\left(\psi+x \frac{\partial \psi}{\partial x}\right) \\
& =\frac{\partial \psi}{\partial x}+x \frac{\partial^{2} \psi}{\partial x^{2}}+\frac{\partial \psi}{\partial x} \\
& =2 \frac{\partial \psi}{\partial x}+\frac{\partial^{2} \psi}{\partial x^{2}}
\end{aligned}
$$


- plume reached altitudes of $\sim 3000$ to 4500 meters above sea level (ASL).

Following the emission of this plume seismicity levels decreased to their lowest in over a month, and the thermal anomaly was no longer apparent on satellite imagery. For these reasons the LCCC was lowered to Yellow on April 28. In the following weeks a few small ash-poor plumes were observed in sateliite data, but no thermal anomaly was seen and seismicity levels remained low. On May 13 at 1025 observers on a boat northeast of the volcano reported a small steam and ash burst to $\sim 300 \mathrm{~m}$ above the summit, and a pilot reported similar activity at 1155 . This activity was associated with a weak thermal anomaly and some possible indications of weak tremor.

On May 19 and again on May 21 tremor pulses were seen in seismic records. Early in the morning of May 24 tremor became continuous and increased to Dr levels of $1 \mathrm{~cm} 2$. At 0700 on May 25 a narrow $10 \mathrm{~km}$-wide ash-rich steam plume was seen in satellite imagery extending $160 \mathrm{~km}$ south from the vent at $\sim 4600$ meters ASL. An earlier pilot report at 2311 the previous night also indicated a plume at the same altitude. Because of these observations, the LCCC was raised to Orange at 0930 on May 25. The plume persisted in satellite imagery with lengths varying from 110 to $160 \mathrm{~km}$ throughout the day, and a pilot report at 1603 indicated that the plume was at 5500 meters ASL. On May 26 the plume migrated to a southeasterly tract, and by 1645 had lengthened to $450 \mathrm{~km}$. By 0100 on May 27 the plume extended $800 \mathrm{~km}$ to the east-southeast. After this time the plume dettached from the volcano, roughly at the same time as a peak in tremor levels (Dr $\sim 2 \mathrm{~cm} 2)$ ). By 0300 the plume had dissipated downwind, and tremor levels receded to $\mathrm{Dr}$ levels of $\sim 0.5 \mathrm{~cm} 2$. 
. 


$$
\text { A Goorte- jop- This could be turbed into }
$$

Dörte Mann

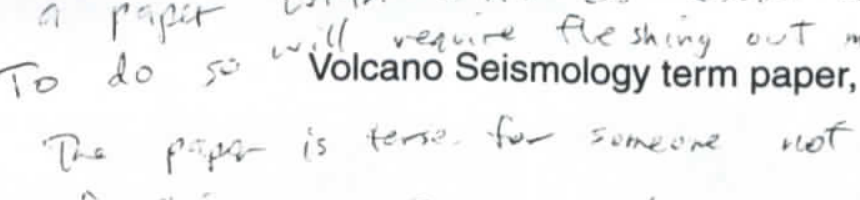

$$
\begin{aligned}
& \text { samilien with the procedure. }
\end{aligned}
$$

\title{
The Duration - Amplitude Distribution of Tremor at Shishaldin Volcano
}

\begin{abstract}
The duration-amplitude distribution for 8 tremor episodes during the current activity of Shishaldin volcano (7April to 23 April 1999) was examined. An exponential rather than a power-law model is found to be the best fit to the data. Correlation is especially good for tremor accompanying eruptive sequences. The characteristic amplitude of the distribution, $\lambda^{-1}$, varies between $0.20 \mathrm{~cm}^{2}$ for non-eruptive episodes, and $6.66 \mathrm{~cm}^{2}$ for the eruption on April 19/20. The extremely fast decrease in tremor amplitude on April 23 suggests a sudden decease of its source, interpreted as the closure of the magma conduit.
\end{abstract}

\section{Introduction}

\subsection{Current activity of Shishaldin volcano}

Shishaldin volcano is located in the eastern Aleutians on Unimak Island (Fig. 1). It is one of the most active volcanoes in the Aleutian arc, and has erupted at least 28 times since 1775.

The current activity started with slightly elevated seismicity at the end of January 1999. In mid

february low-level seismic tremor as well as a thermal anomaly in satellite imagery was identified. On April 19, tremor increased dramatically when a significant eruption with plume heights up to 45,000 ft occured. The eruption lasted about 7 hours. Another explosive eruption occured on April 22, again accompanied by rapid increase in tremor levels. A detailed chronology of tremor occurence and eruptive activity from February 18 to April 23,1999, is given in Table 1. 


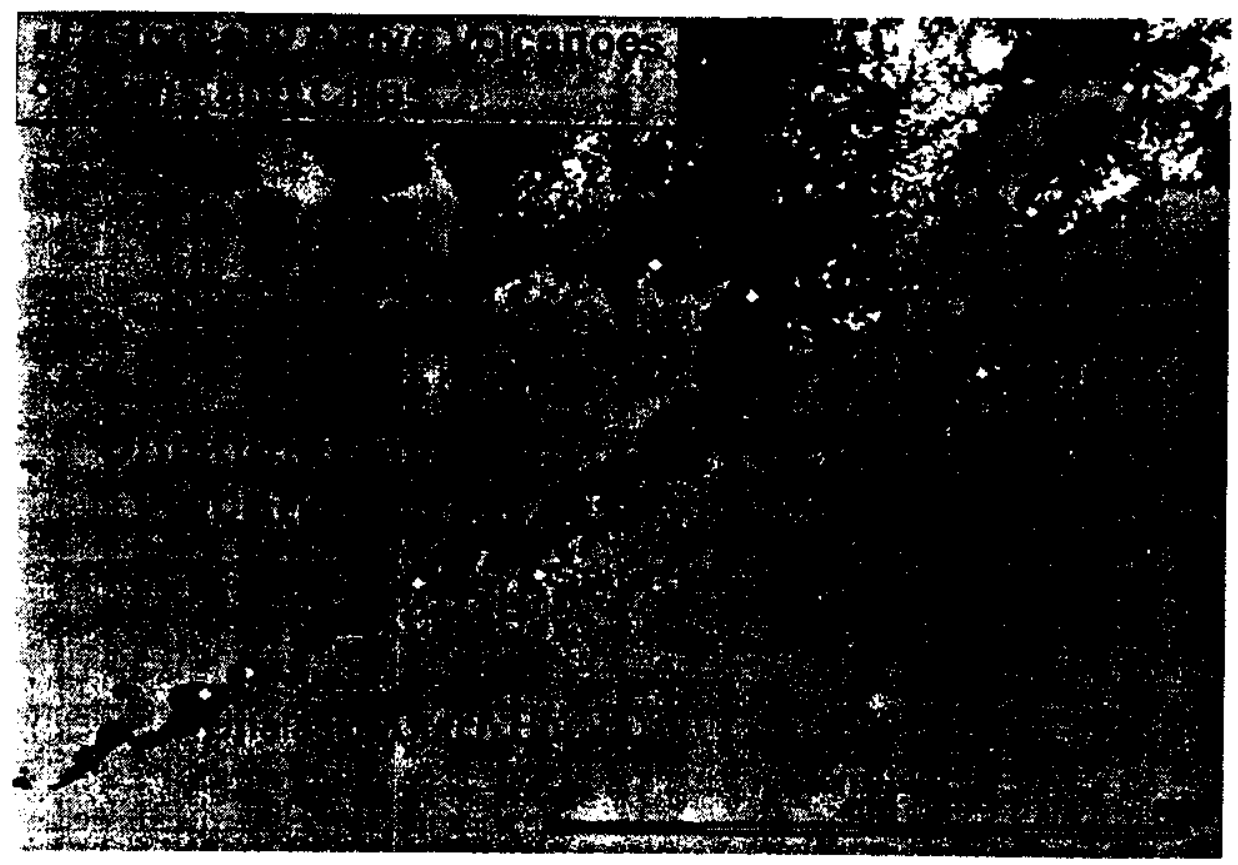

Fig. 1: Location of Shishaldin volcano [From: Alaska Volcano Observatory (AVO) Public Web Page]

Table 1: Tremor during Shishaldin activity (CC denotes Level of Concern Color Code, as released by AVO; $\mathrm{Dr}$ is tremor amplitude given as reduced displacement)

\begin{tabular}{|c|c|}
\hline 18 Feb 99 & $\begin{array}{l}\text { Low level tremor, persistence of thermal anomaly in satellite images } \\
\text { CC: yellow }\end{array}$ \\
\hline 07 April 99 & $\begin{array}{l}\text { 16:00 utc: Tremor substantially increased above previous levels, up to } \mathrm{Dr}=10 \\
\mathrm{~cm}^{2} \text {, then decreasing and returning to previous levels about } 8 \mathrm{hrs} \text { later; } \mathrm{CC} \text { : } \\
\text { orange }\end{array}$ \\
\hline 13 April 99 & 05:00 utc: Tremor markedly increased, level fluctuates for $24 \mathrm{hrs}$, then decreases \\
\hline 18 April 99 & General tremor increase, fluctuation at elevated level \\
\hline 19 April 99 & $\begin{array}{l}\text { 19:33 utc: drasticat increase up to } \mathrm{Dr}=20 \mathrm{~cm}^{2}, 4 \text { peaks during } 7 \mathrm{hr} \text { eruption, then } \\
\text { decrease; CC: red }\end{array}$ \\
\hline 20 April 99 & $\begin{array}{l}11: 45 \text { utc: tremor declines abruptly and begins to increase again at 24:00 utc; } \mathrm{CC} \text { : } \\
\text { orange }\end{array}$ \\
\hline 21 April 99 & Tremor at level of 19 April pre-eruption; CC: red \\
\hline 22 April 99 & $\mathrm{CC}$ : orange, then red again \\
\hline 23 April 99 & $\begin{array}{l}\text { 05:00 utc: eruption, tremor levels increase up to } \mathrm{Dr}=50 \mathrm{~cm}^{2} \text {, then decrease } \\
\text { abruptly to levels below } \mathrm{Dr}=2 \mathrm{~cm}^{2}\end{array}$ \\
\hline
\end{tabular}




\subsection{The duration amplitude distribution of volcanic tremor}

The duration-amplitude relationship of volcanic tremor is equivalent to the frequency-size distribution that characterizes most phenomena in nature. Some of them, like earthquakes, rock fragments (e.g. volcanic ash and pumice), and volcanic eruptions can be described by a power-law model [Gutenberg and Richter, 1954; Hartman, 1969; Simkin, 1993]. Others, like volcano spacing [Vogt, 1974], are described best with an exponential distribution.

The power-law describes source processes that do not involve a characteristic scale, while source processes of exponential distributions are scale-bounded [e.g. Turcotte, 1992].

Benoit et al. [1998a] found in several case studies a better fit of the exponential model, when applied to volcanic tremor data.

In this paper, both models are applied to several tremor episodes during the current activity of Shishaldin volcano. It will be shown that the exponential model gives the better fit for all of the episodes. The characteristic amplitude will be determined and used for further interpretation.

\section{Method}

'is.....

Sinee tremor is a continuous signal, we can't simply count the events of a particular size and plot the number versus size. Therefore, tremor duration is used as an analog, and the duration at a particular amplitude or greater is measured.

Tremor amplitude is measured as reduced displacement (Dr). It accounts for instrument magnification, distance to the source, and the type of waves composing the tremor. In this study, Dr is based on surface waves, and defined as [Fehler, 1983]: 


$$
D r=\frac{A}{2 \sqrt{2}} \cdot \frac{\sqrt{r \lambda}}{M}
$$

where $A$ is the peak-to-peak ground displacement, $r$ is the distance between source and receiver, $M$ is the instrument magnification, and $\lambda$ is the wavelength.

The data were derived from the IceWeb near-real-time monitoring system [Benoit et al., 1998a], and a scale was used to measure the duration of amplitudes greater than or equal to selected values. The cumulative duration was then plotted against the amplitude, using a log-linear as well as a log-log scaling.

An exponential distribution of the form

$$
d(D r)=d_{t} e^{-\lambda D r}
$$

where $d$ is the total duration of tremor with amplitudes greater than or equal to $\mathrm{Dr}, d_{t}$ is the total duration of tremor during the period studied, and $\lambda$ is a scaling parameter, will result in a linear correlation in the log-linear case. A power-law distribution of the form

$$
d(D r)=d_{t}(D r)^{-\gamma}
$$

where the parameter $\gamma$ can be related to the fractal dimension of the amplitudes, will result in a linear correlation in the $\log -\log$ case. The correlation coefficient $\mathbf{R}$ is calculated to determine the best fitting model.

Eight tremor episodes were selected for analysis, and are listed in Table 2. The selected seismic station is the one that best mimics the general data trend for all stations during that time. In most cases, ISTK was the best choice, except for the pre-eruptive tremor period on April 18 and 19 (Episode III). The four peaks in tremor amplitude during the eruption on April 19 to 20 (Episodes IV and V), were investigated using stations ISTK and SSLW, to assure good results.

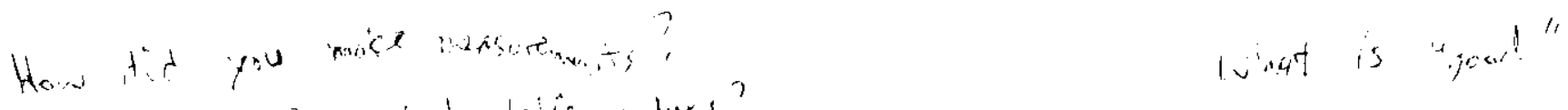

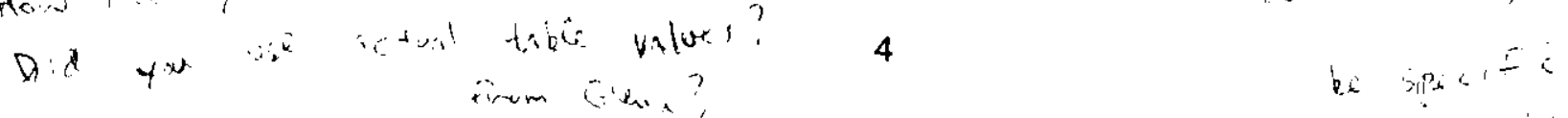


Table 2: Tremor episodes used in this study

\begin{tabular}{|c|c|c|c|}
\hline Episode & Date (April 99, utc time) & Station & Volcanic activity \\
\hline \hline I & $7(05: 00-12: 00)$ & ISTK & non-eruptive $\vdots$ \\
\hline II & $7(15: 30-20: 00)$ & ISTK & 1st subst. increase (eruption?) \\
\hline III & $18(00: 00)-19(12: 00)$ & SSLN & pre-eruptive \\
\hline IV & $19(17: 49-21: 00)$ & ISTK, SSLW & eruption, peaks 2, 3, 4 \\
\hline V & $19(21: 00)-20(12: 00)$ & ISTK, SSLW & pre-eruptive \\
\hline VI & $22(18: 00)-23(04: 00)$ & ISTK & eruption \\
\hline VII & $23(04: 00-11: 00)$ & ISTK & abrupt tremor decrease \\
\hline VIII & $23(10: 00-11: 00)$ & ISTK & Peak 1 \\
\hline
\end{tabular}

Appendix A shows a Dr - plot spanning the whole time from April 7 to April 24, 1999. The tremor episodes considered in this study are marked with horizontal bars.

\section{Results}

Figs. 2 to 9 show the duration-amplitude distribution for all $\forall 甘 \mid$ episodes, applying an exponential as well as a power-law. Visual analyzation already suggests a better fit of the exponential model. Correlation coefficients range from $R=0.91$ to 1.00 , and from $R=0.81$ to 0.97 for the exponential and power-law distribution respectively. They are always larger for the exponential model. The difference is especially significant for the eruptive periods V, VII, and VIII, while for the non-eruptive periods I and VI the correlation coefficients are more similar (Table 3).

Therefore, the exponential law is declared to give the best fit, and equation (2) was used to calculate the characteristic tremor amplitude $\lambda^{-1}$. Its values range from $0.20 \mathrm{~cm}^{2}$ during the relatively quiet presumably non-eruptive episode I on April 7, to $6.66 \mathrm{~cm}^{2}$ during the vigorous 
eruption on April 19 - 20 (Table 4) . Co-eruptive episodes IV, V, VII, and VIII, show the highest values. Episode VI, between the two eruption phases, has a significantly lower value, but remains above those for the early episodes I to III.

Table 3: Comparison of correlation coefficients $\mathrm{R}$ for exponential and power-law model. Epsidoes IV and V show values for stations ISTK and SSLW

\begin{tabular}{|c|c|c|}
\hline Episode & $\mathrm{R}(\exp )$ & $\mathrm{R}(\mathrm{pow})$ \\
\hline \hline $\mathrm{I}$ & 0.98 & 0.97 \\
\hline II & 0.97 & 0.93 \\
\hline III & 0.94 & 0.89 \\
\hline IV & $0.99 / 1.00$ & $0.93 / 0.97$ \\
\hline V & $0.91 / 0.98$ & $0.85 / 0.81$ \\
\hline VI & 0.97 & 0.95 \\
\hline VII & 0.93 & 0.81 \\
\hline VIII & 0.95 & 0.82 \\
\hline
\end{tabular}

Table 4: Characteristic tremor amplitudes for an exponential model. Episodes IV and V show vạlues for stations ISTK and SSLW

\begin{tabular}{|c|c|}
\hline Episode & characteristic amplitude $\left(\lambda^{-1}\right)\left[\mathrm{cm}^{2}\right]$ \\
\hline \hline I & 0.2042 \\
\hline II & 0.6037 \\
\hline III & 0.4468 \\
\hline IV & $3.4965 / 4.1929$ \\
\hline V & $3.9698 / 6.6622$ \\
\hline VI & 2.1299 \\
\hline VII & 5.1787 \\
\hline VIII & 4.7962 \\
\hline
\end{tabular}




\section{Discussion and Conclusions}

The better fit of the exponential model supports the observations by Aki and Kayanagi (1981) and Benoit et al. (1998a), that the duration-amplitude distribution of volcanic tremor is best described by an exponential law.

The relatively low value of $0.60 \mathrm{~cm}^{2}$ for the characteristic amplitude $\lambda^{-1}$ during the first substantial increase of tremor on April 7 (Episode II) suggests, that this episode was not related to an explosive eruption. No visual observations exist to confirm or disprove this hypothesis.

An interesting feature is the abrupt decline in tremor amplitude on April 23 between 10:00 and 11:00 utc (Episode VIII). Considering $\lambda^{-1}=4.80 \mathrm{~cm}^{2}$, the tremor seems to be co-eruptive. The decline from $\mathrm{Dr}>18 \mathrm{~cm}^{2}$ to $\mathrm{Dr}<2 \mathrm{~cm}^{2}$ within 30 minutes, and then remaining at about that level until present could indicate the sudden closure of the conduit. This leaves room for speculations, under which conditions this happened and whether magma is now accumulating in a plugged conduit, or if the magma source itself 'dried up'. The former means that another very explosive event could happen in the near future, the latter means, that the eruption is over.

The application of the exponential model also implies that the tremor source is scale bound. This scaling can be due to a fixed source geometry driven by a variable excess pressure, or to a fixed pressure with variable soucre geometry. Additional information like tremor spectrum variation with time could be used to constrain the source geometry.

\section{References}

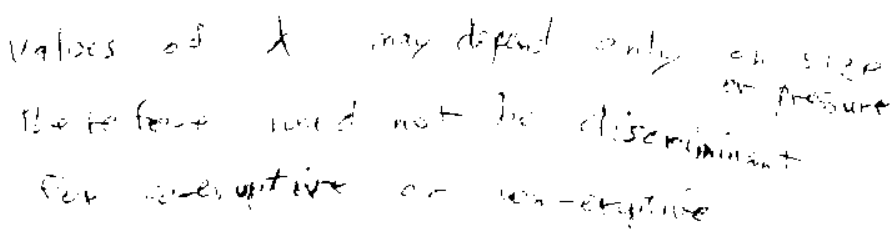

Aki, K., and R.Y. Kayanagi. Deep volcanic tremor and magma ascent mechanisms under Kilauea, Hawaii. J. Geophys. Res., 86, 7095-7109, 1981

Alaska Volcano Observatory public web page (http://www.avo.alaska.edu) 
Benoit, J.P., S.R. McNutt, and V. Barboza. The duration-amplitude distribution of volcanic tremor. submitted to J. Geophys. Res., 1998 a

Benoit, J.P., G. Thompson, K. Lindquist, R. Hansen, S.R. McNutt. Near-Real-Time WWW-based monitoring of Alaskan volcanoes. Poster presented at AGU Fall meeting, 1998b

Fehler, M. Observations of volcanic tremor at Mt. St. Helens volcano. J Geophys. Res., 88, 34763484,1983

Gutenberg, B., and C.F. Richter. Magnitude and energy of earthquakes. Ann. Geof. 9, 1-15, 1954 Hartmann, W.K. Terrestrial, lunar, and interplanetary rock fragmentation. Icarus, 10, 201-213. 1969

Simkin T. Terrestrial volcanism in space and time. Ann. Rev. Earth. Planet. Sci., 21, 427-452, 1993

Turcotte, D.L. Fractals and chaos in geology and geophysics. Cambridge Univ. Press, 221 p., 1992

Vogt, P.R. Volcano-spacing, fractures, and thickness of the lithosphere. Earth Planet. Sci. Lett., 21, 235-252,1974 


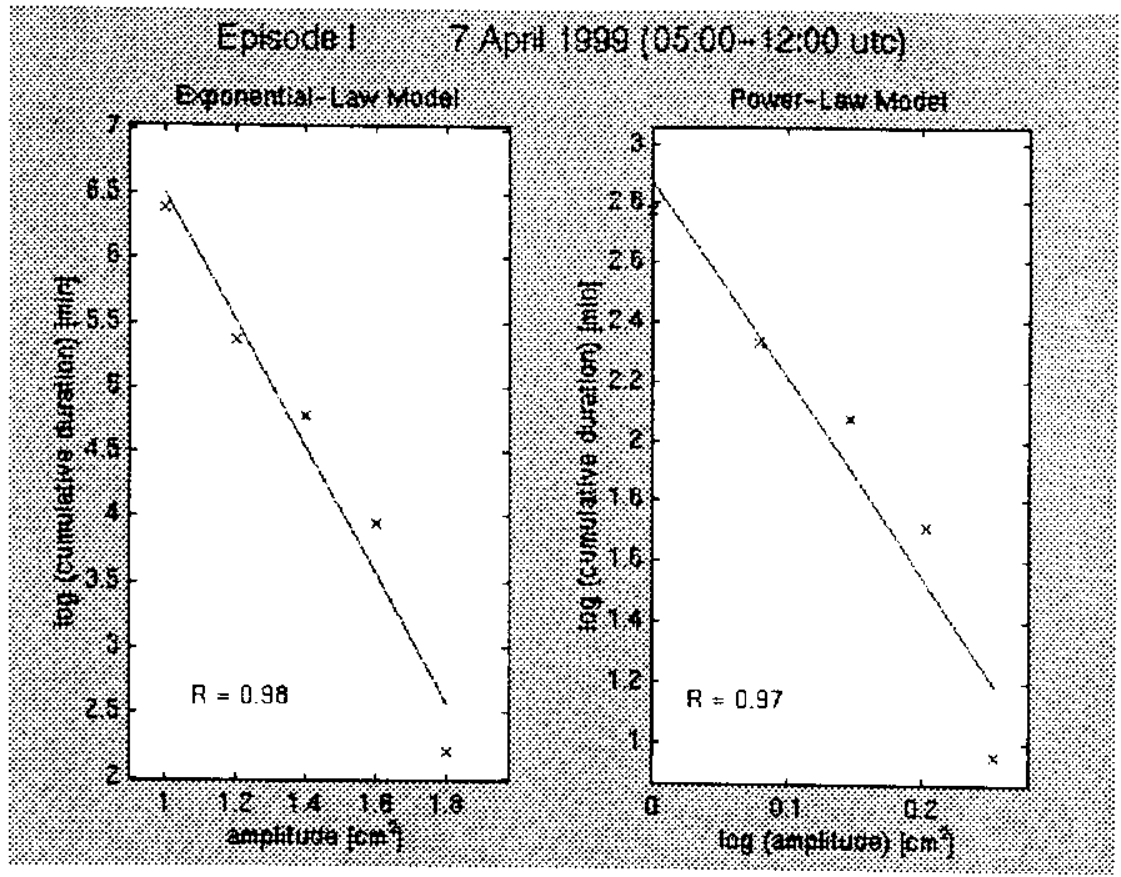

Fig. 2: Duration-amplitude distribution for episode I

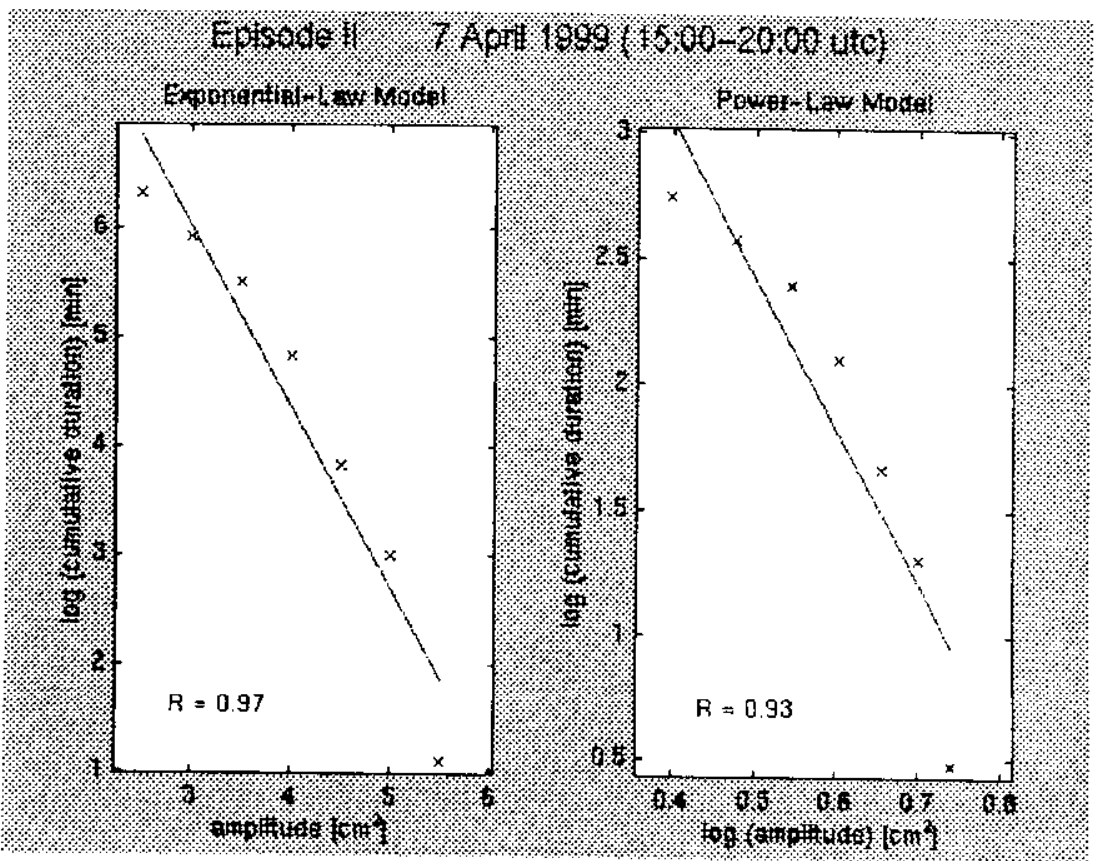

Fig. 3: Duration-amplitude distribution for episode II 


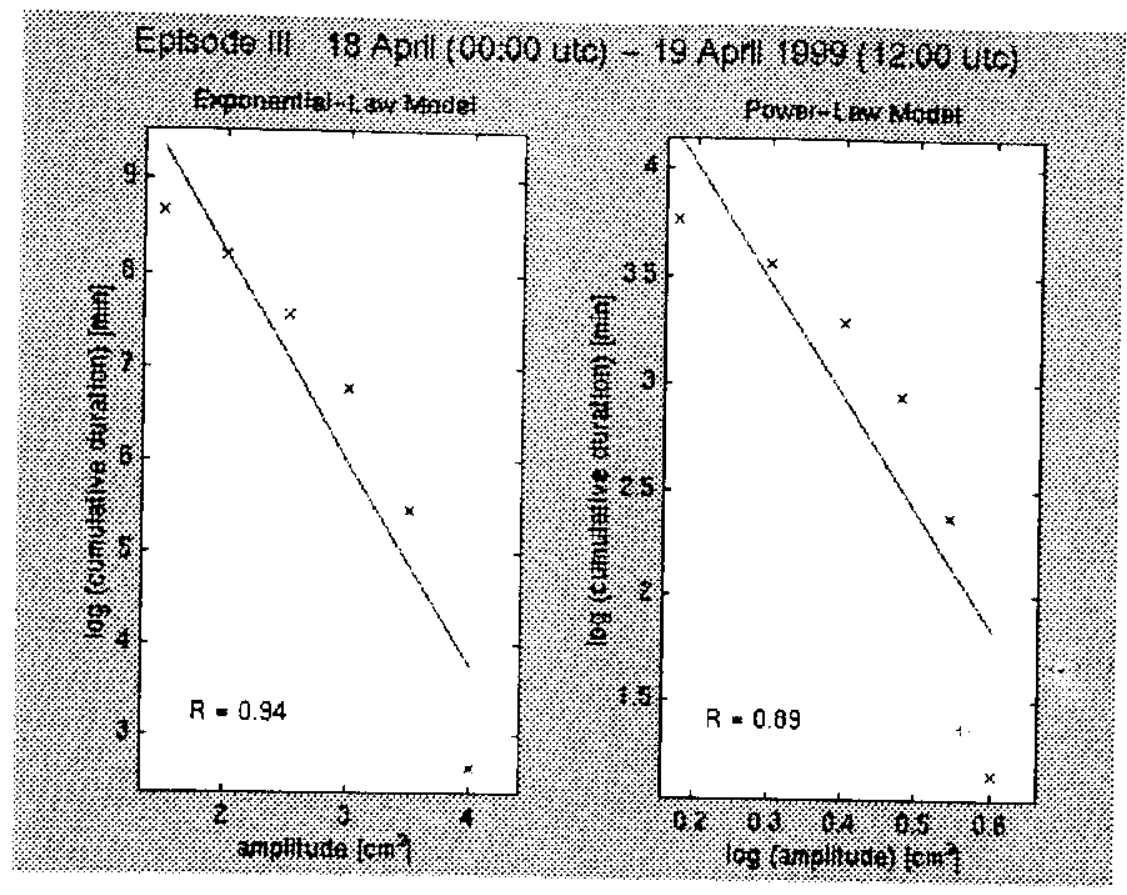

Fig. 4: Duration-amplitude distribution for episode III 

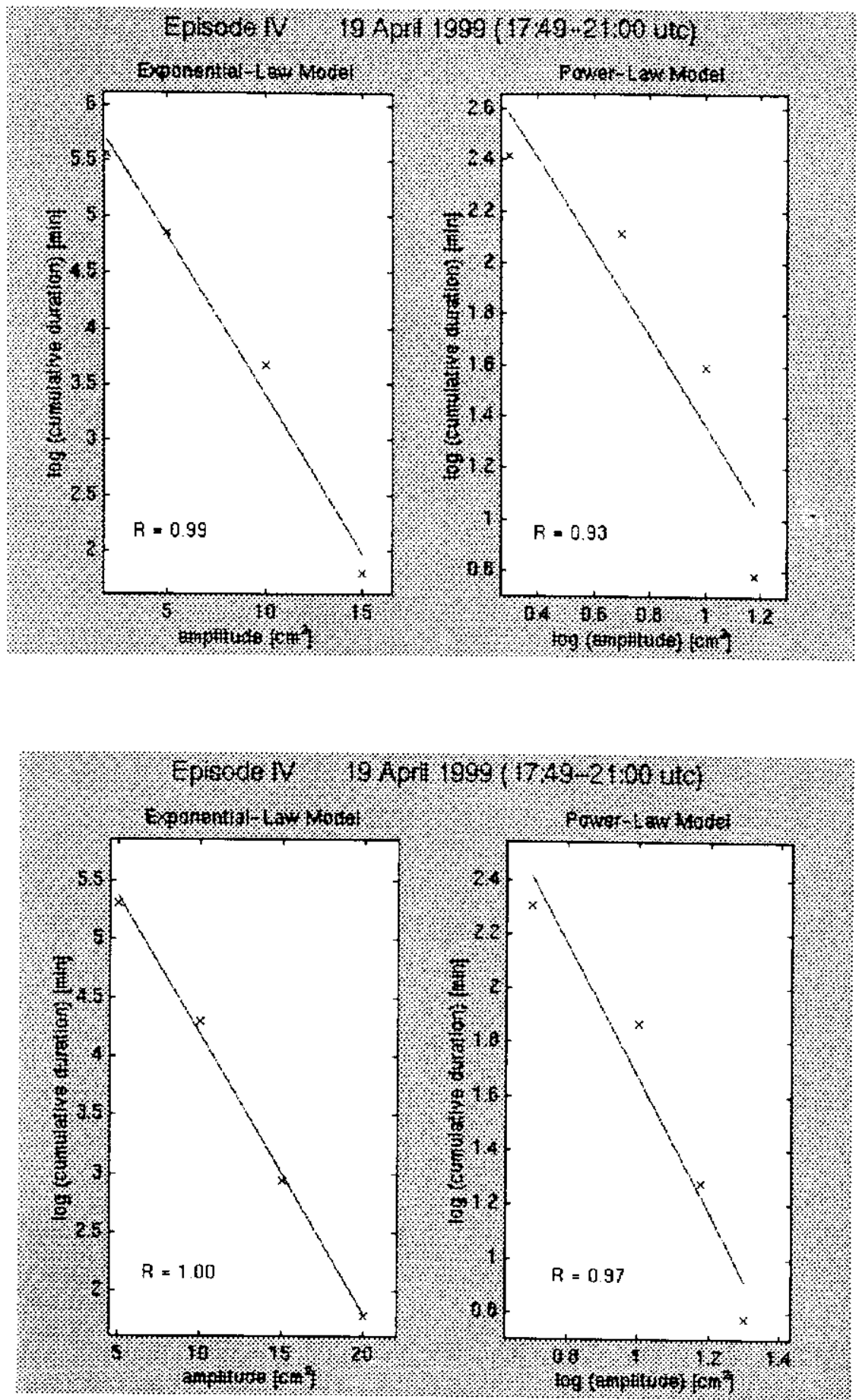

Fig. 5: Duration-amplitude distribution for episode IV. Upper panel: Station ISTK, lower panel: Station SSLW

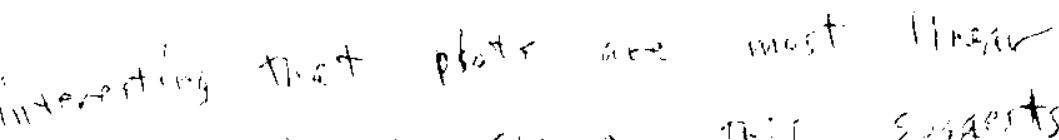

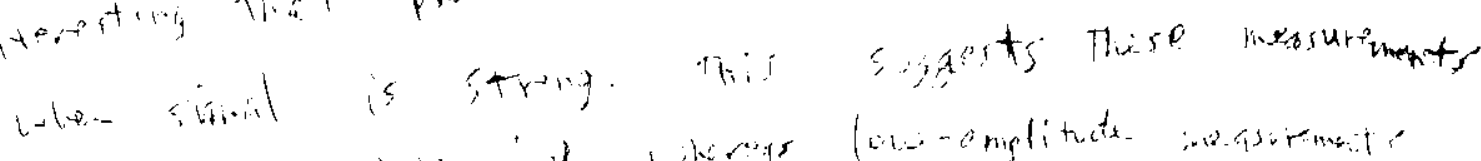

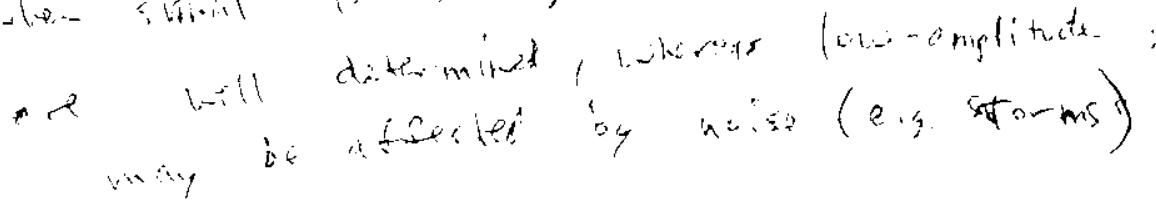



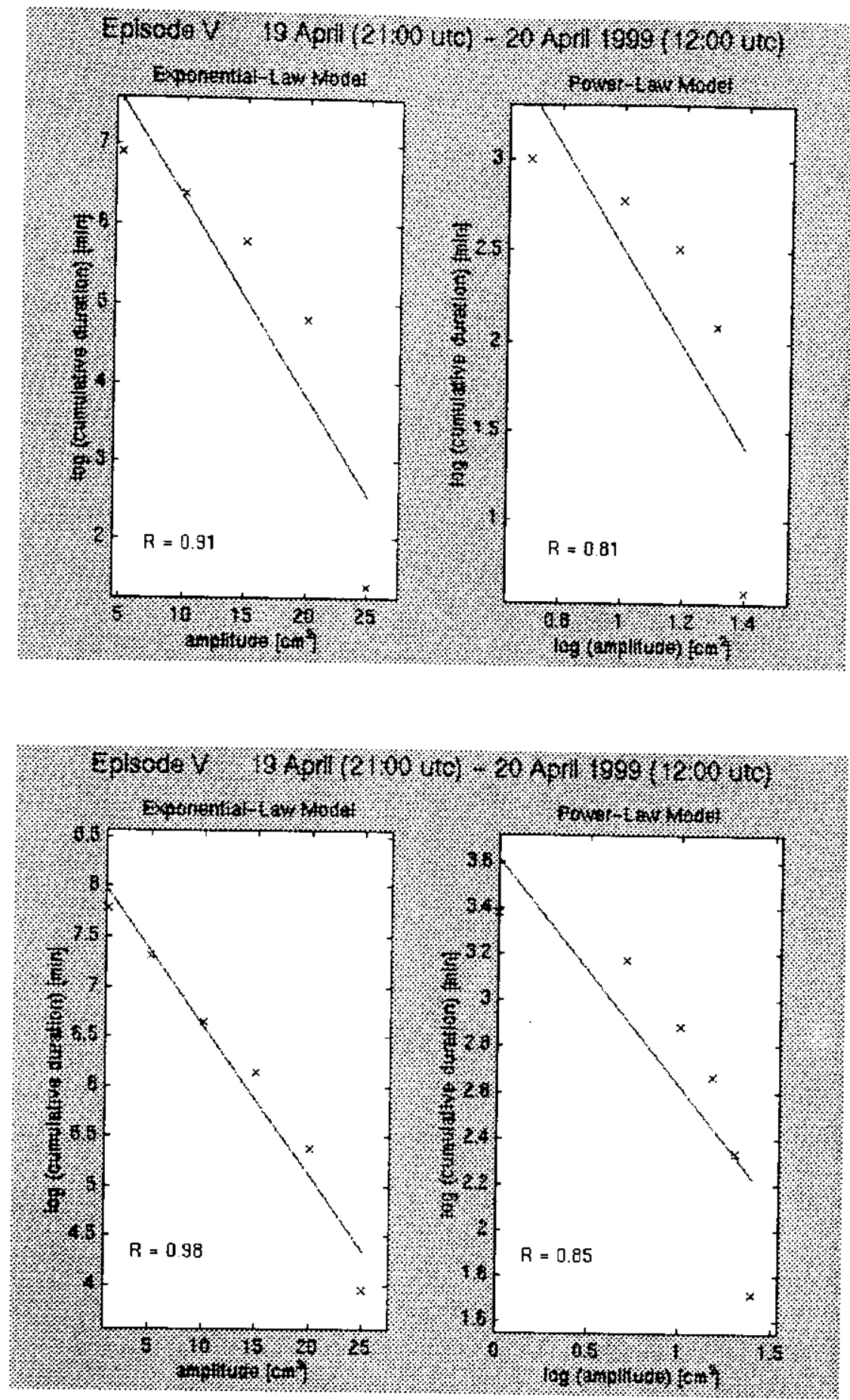

Fig. 6: Duration-amplitude distribution for episode V. Upper panel:

Station ISTK, lower panel: Station SSLW

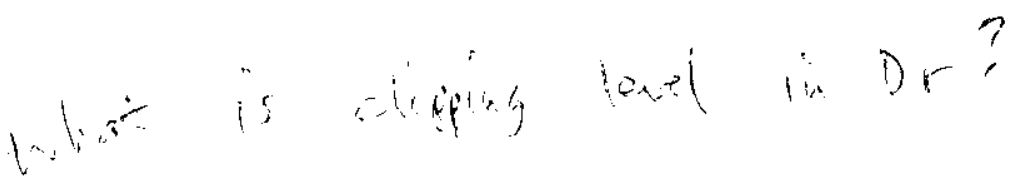




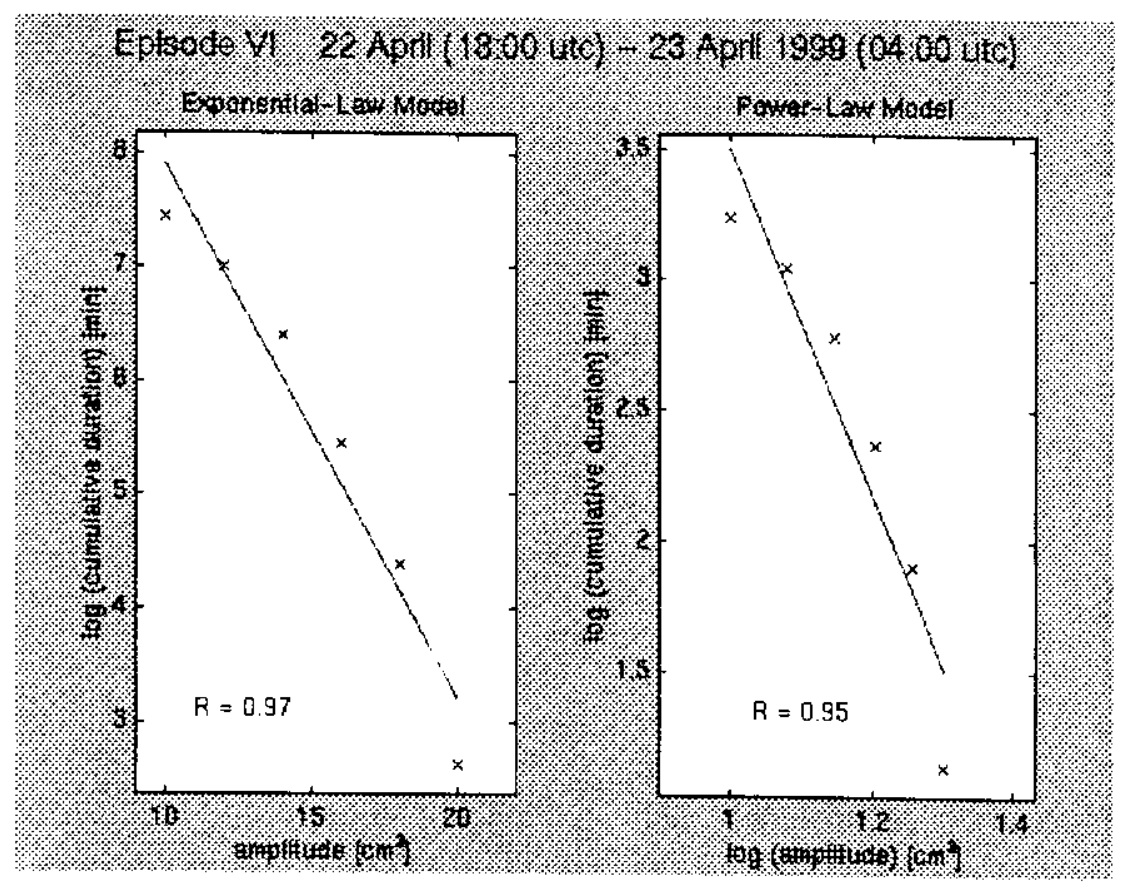

Fig. 7: Duration-amplitude distribution for episode VI. 


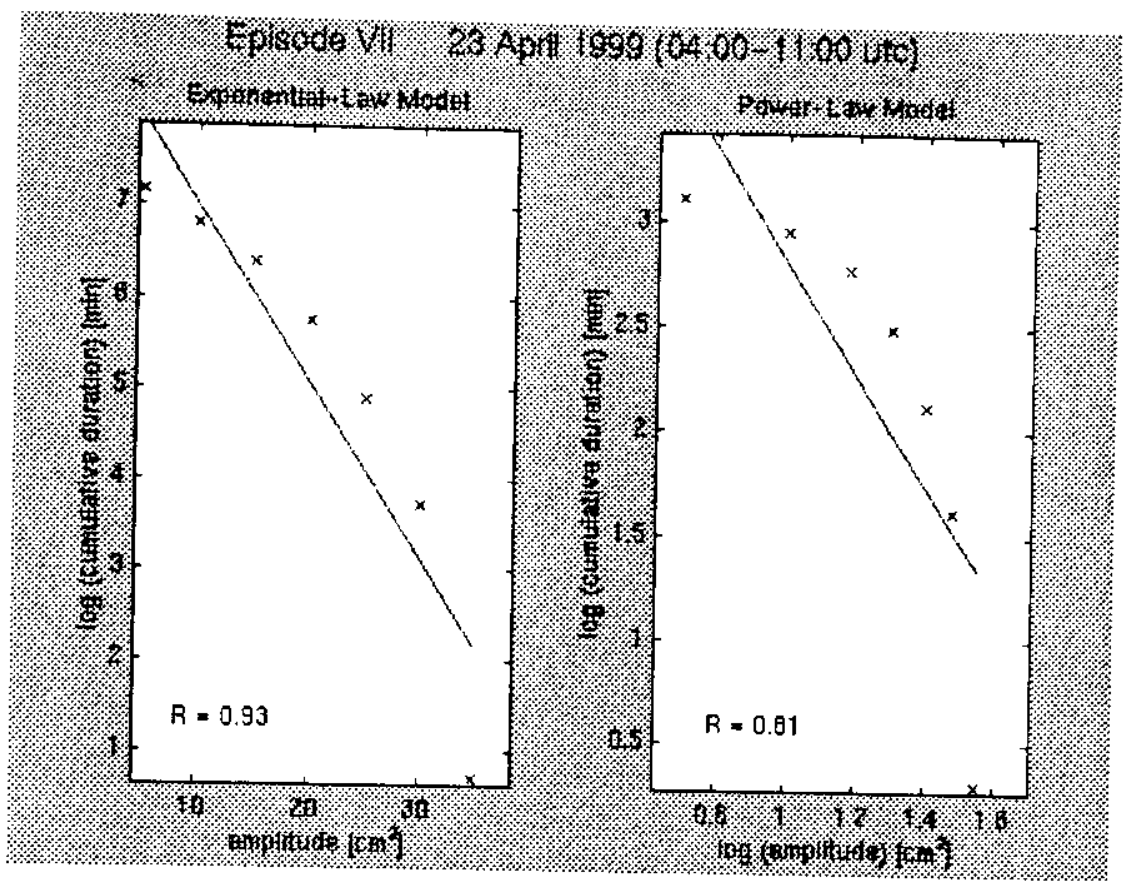

Fig. 8: Duration-amplitude distribution for episode VII

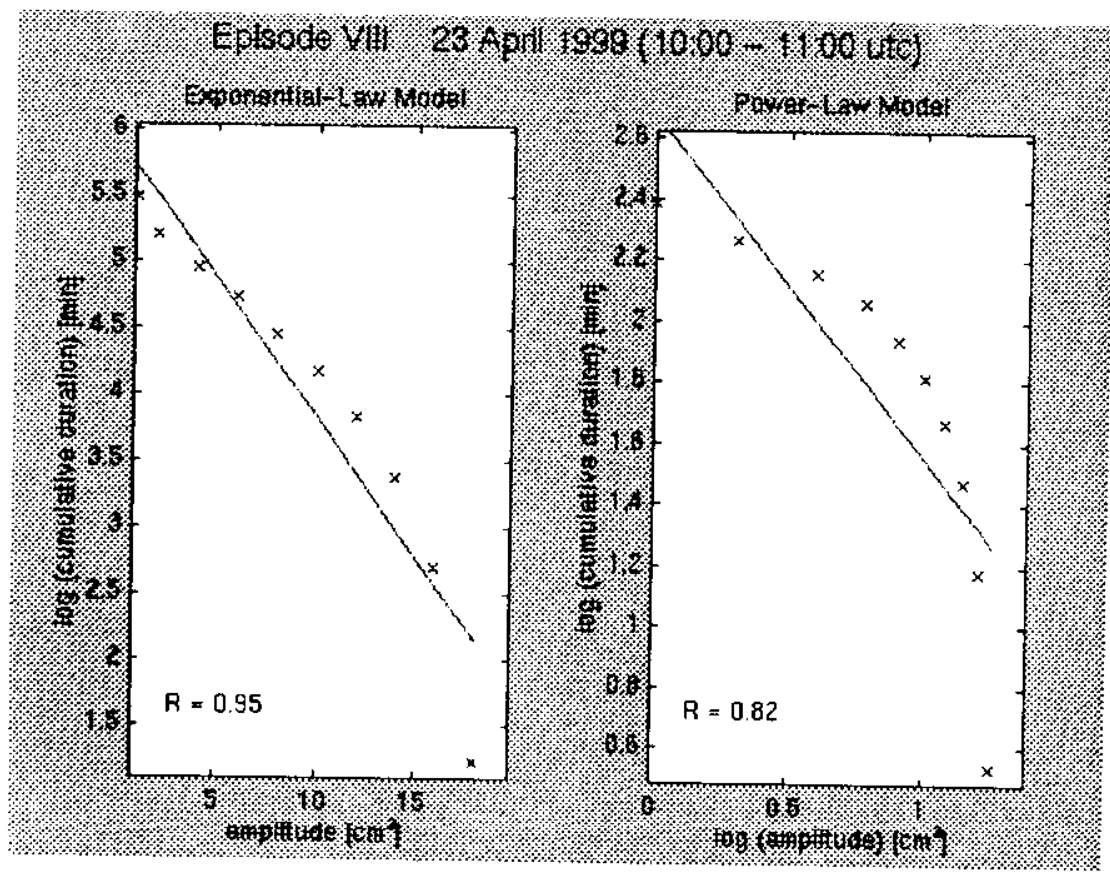

Fig. 9: Duration-amplitude distribution for episode VIII. 


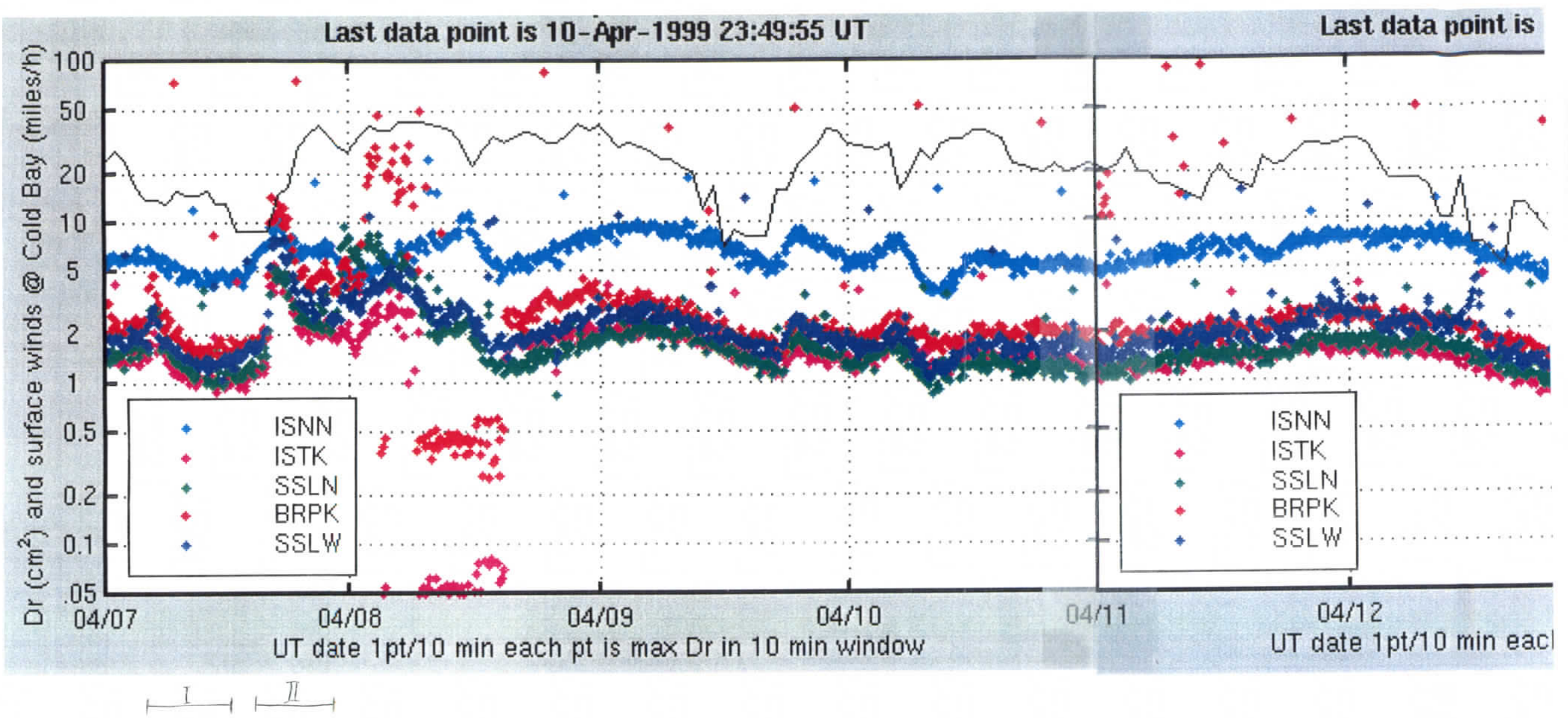




\section{$\checkmark$}




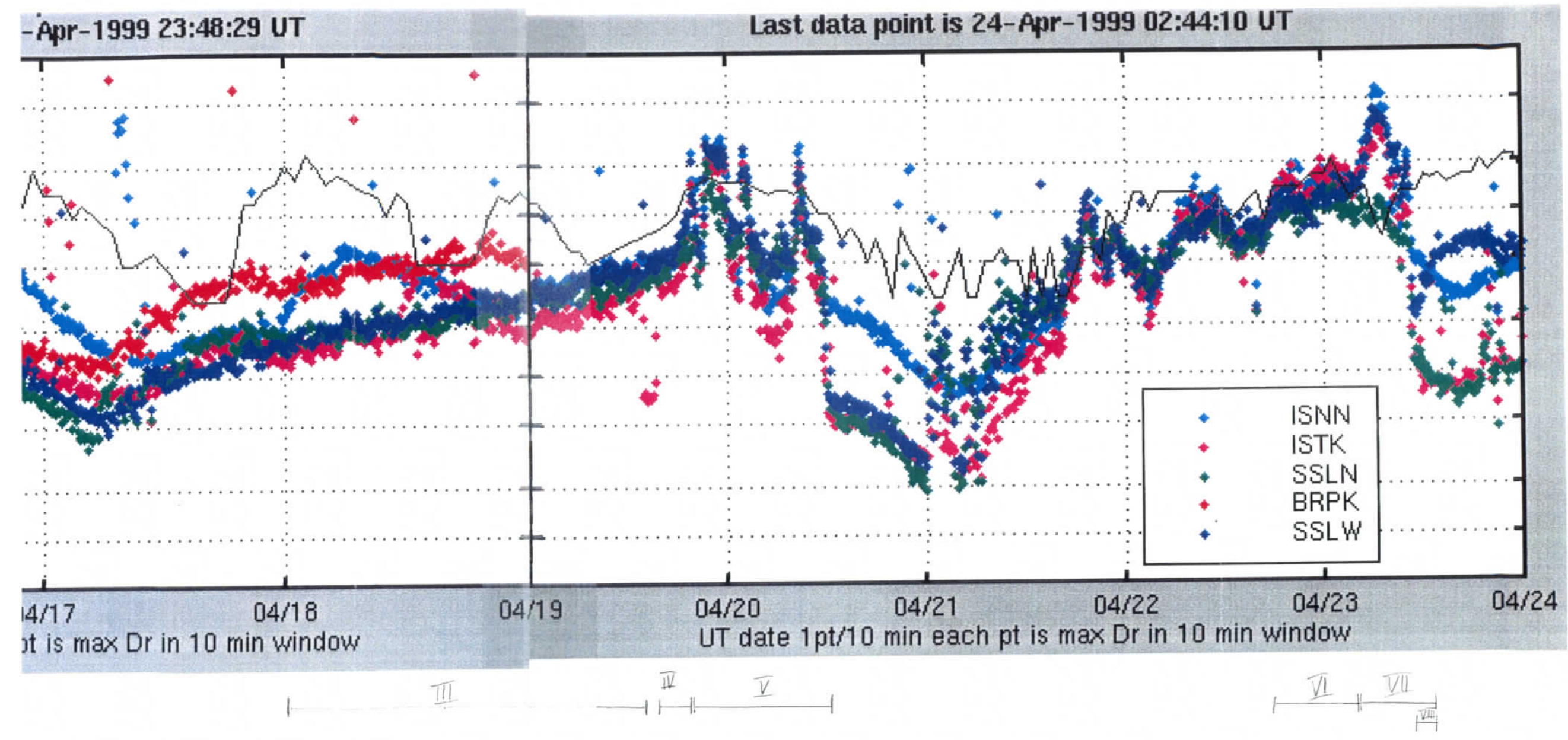




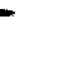
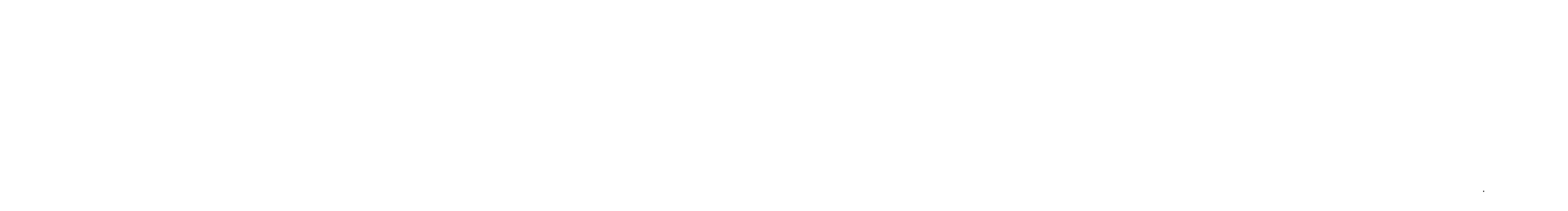

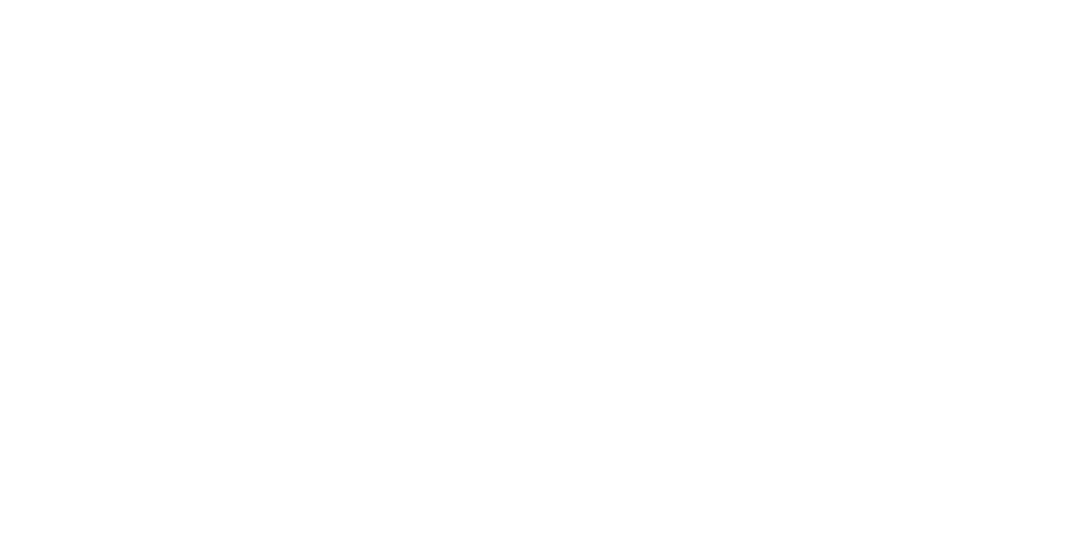
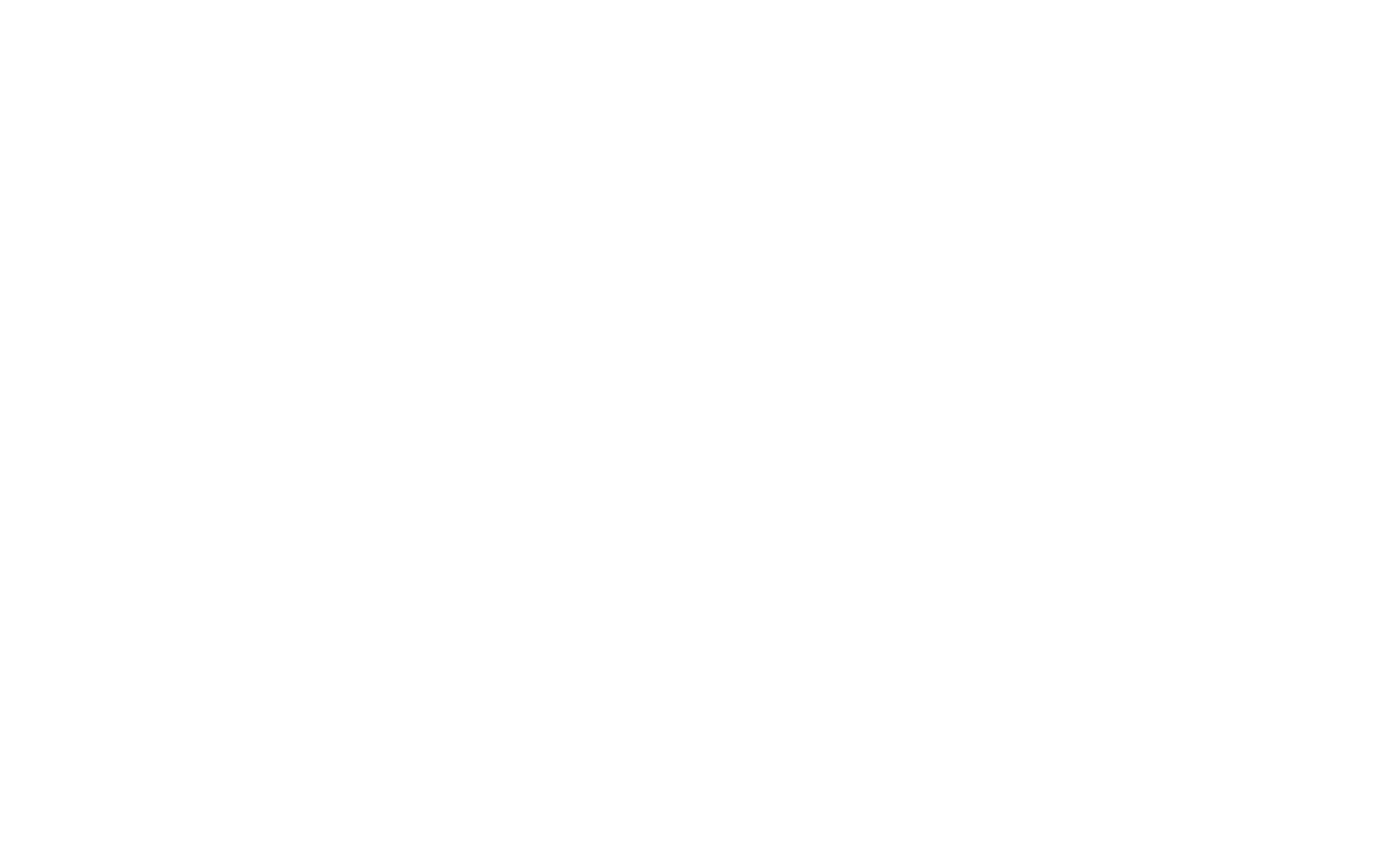

,
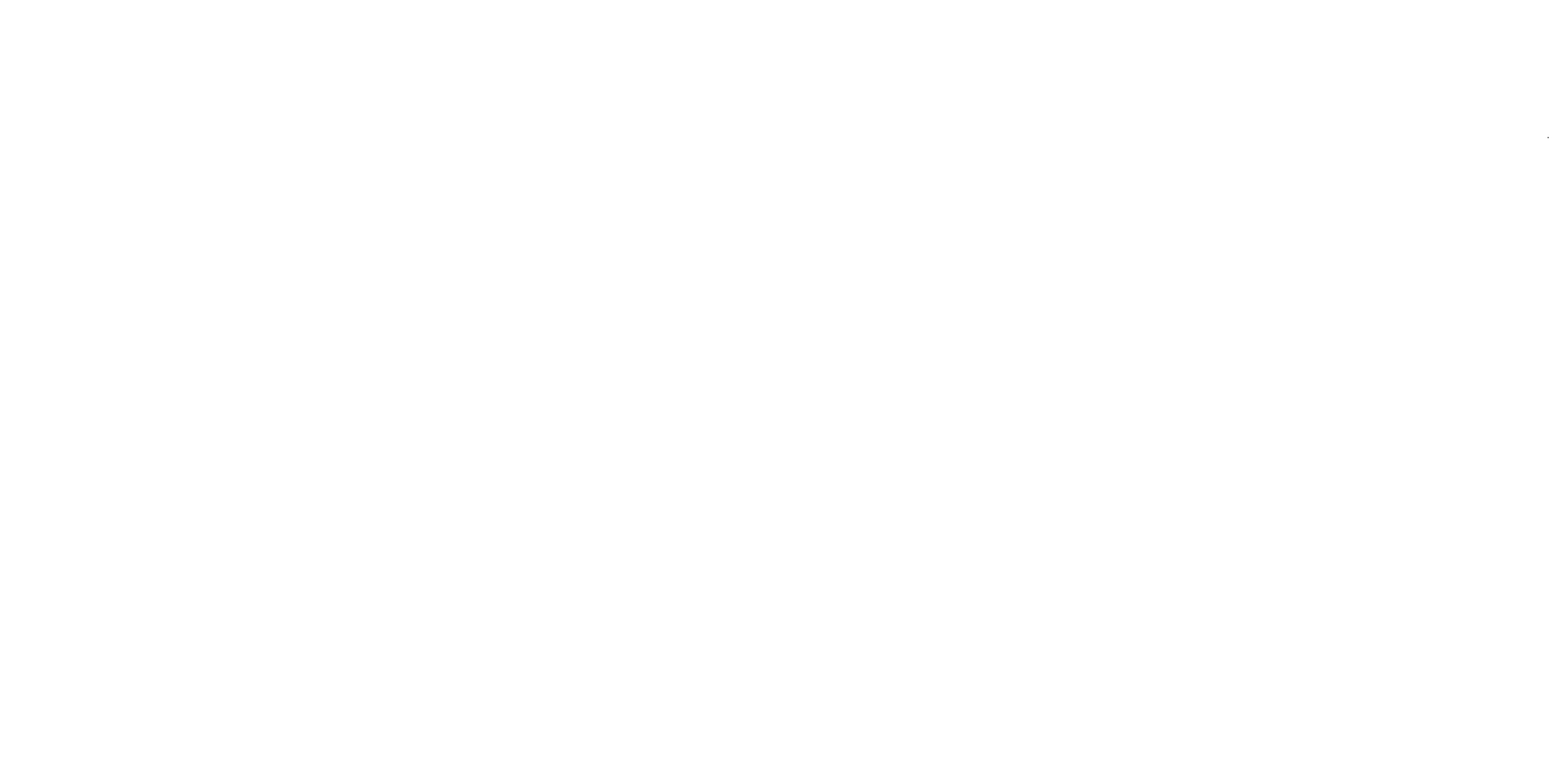

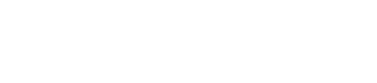


666l KeO UEE|In
06066

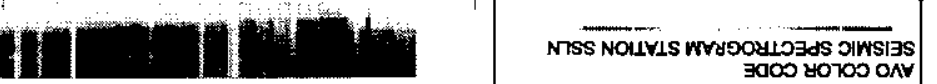

$0 \varepsilon 066$

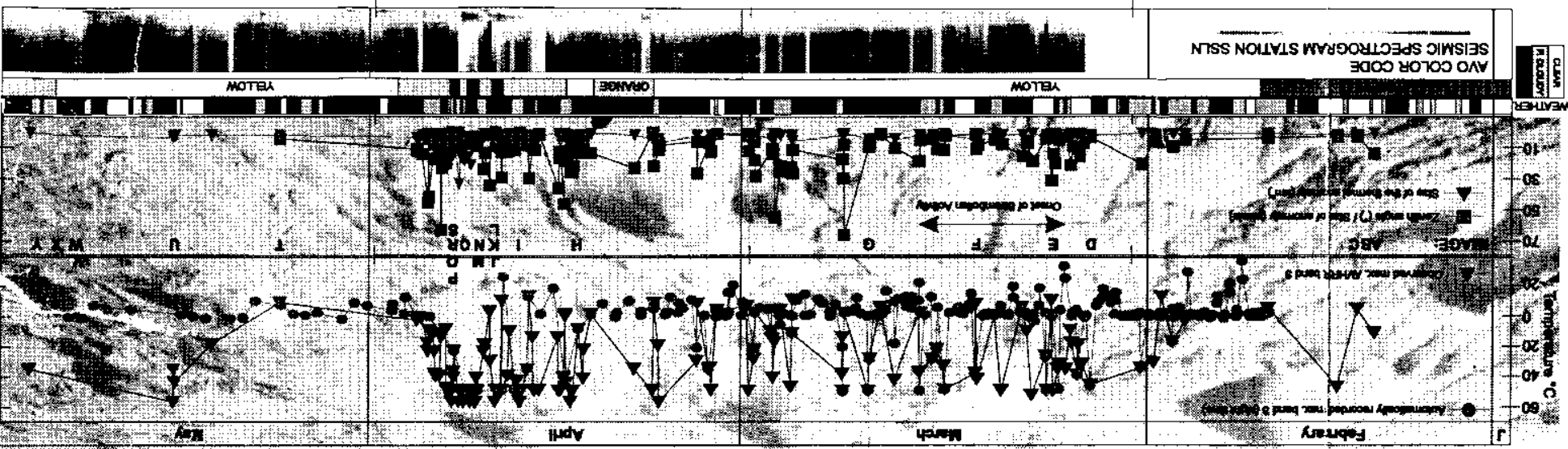

\section{3.

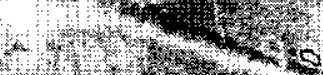

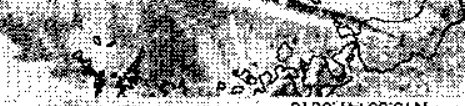

2.
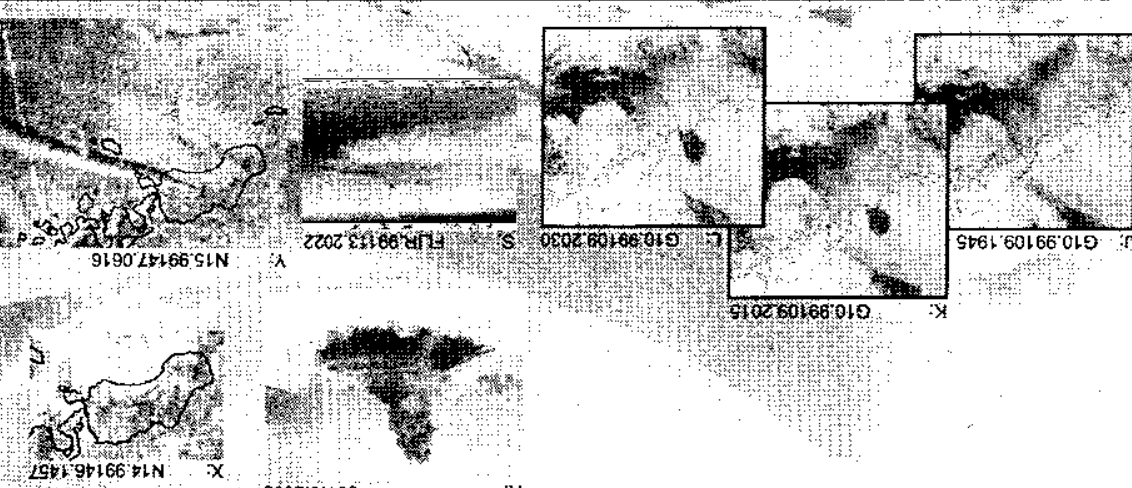$$
\text { sinito: }
$$
astion
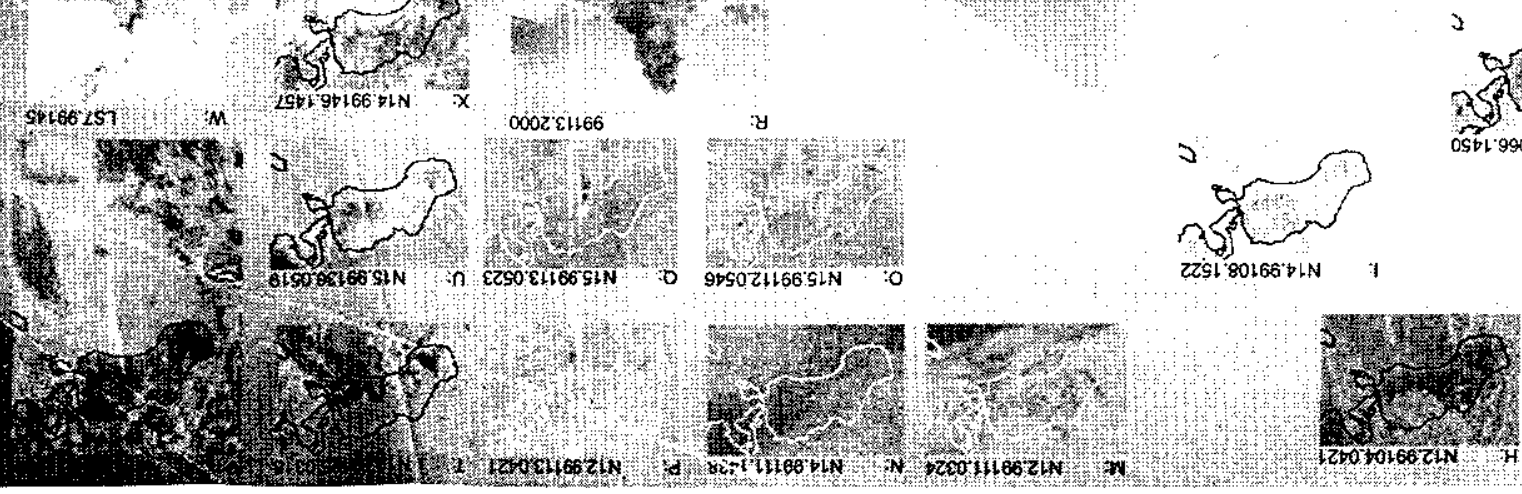

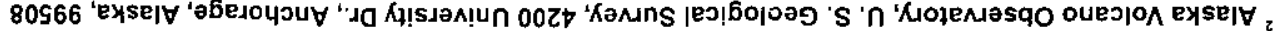

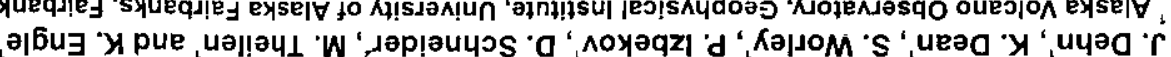

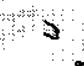

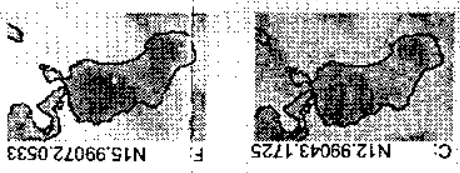
$3 \sqrt{15}$
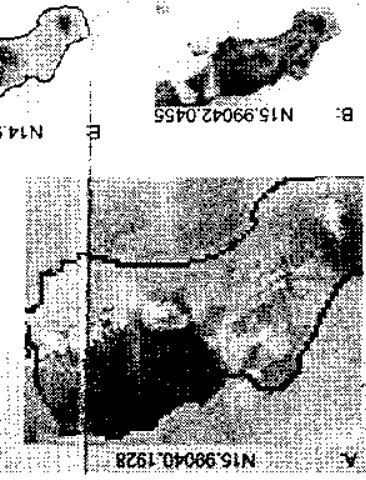

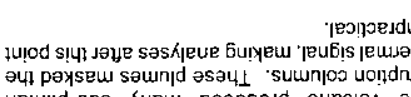

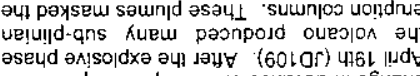

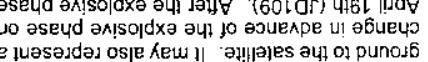

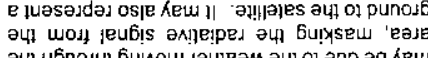

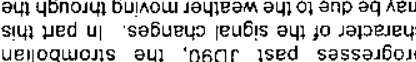

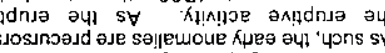

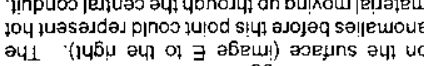

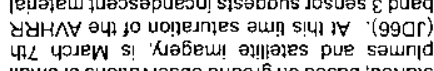

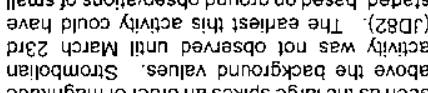
әрп)।

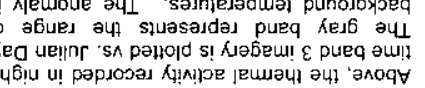
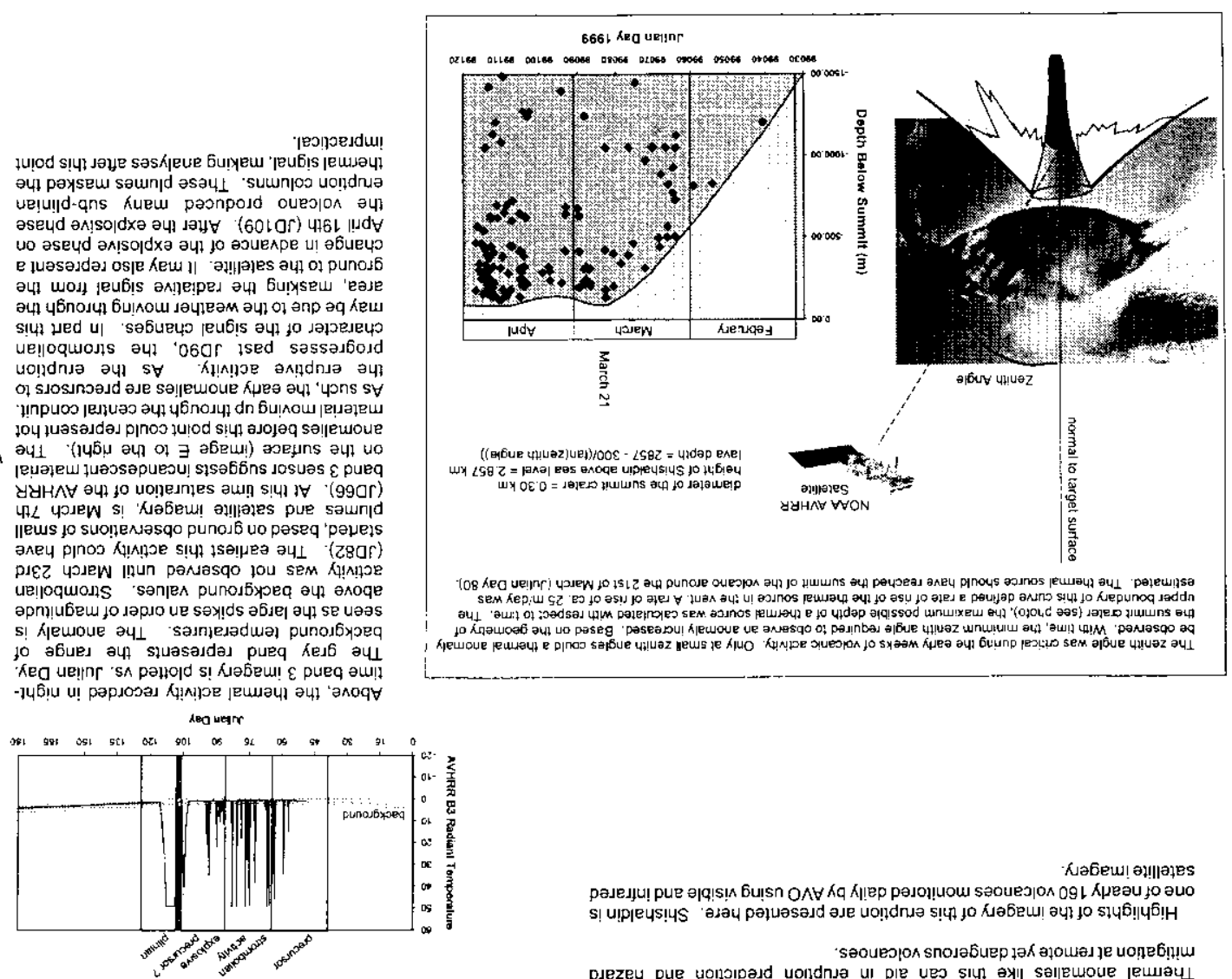

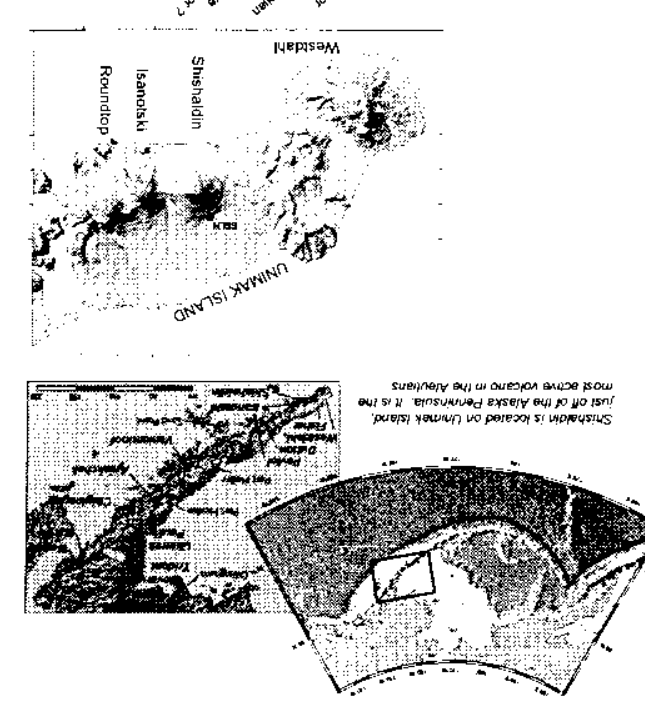

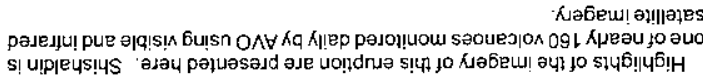

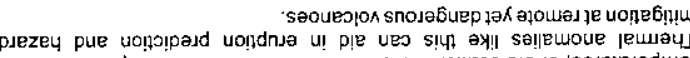

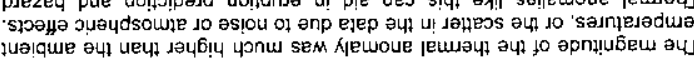

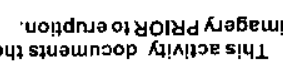

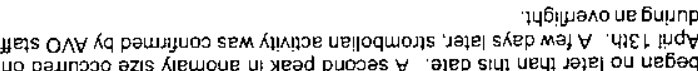

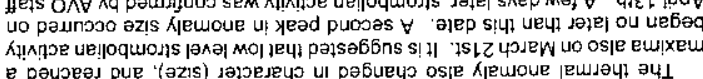

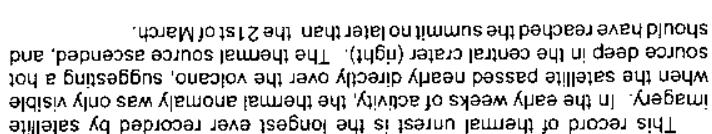

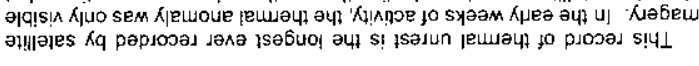

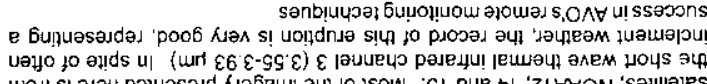

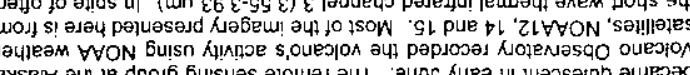

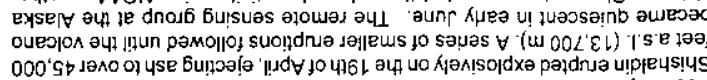

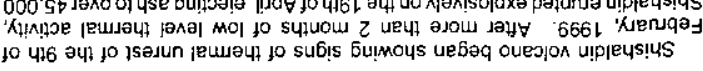


J. Dehn, (Alaska Volcitno Observatory, Geophysical Institute, University of Alaska Fairbanks, Fairbanks, Alaska, 99775-7320: email; jdehn (⿶) gi.alaska.edu) K.G. Dean'. S. Worley', P. Izbekov', D. Schneider ${ }^{2}, M$.Theilen', and K. Engle' ('Alaska Volcano Observatory, Geophysical Institute, University of Alaska Fairhanks,

Fairbanks, Alaska, 9977,5-7320 ${ }^{2}$ Alaska Volcano Observatory, U.S. Geological Survey, 4200 University Drive, Anchorage, Alaska, 99508)

Shishaldin volcano. Unimak Island Alaska, began showing signs of thermal unrest on the $9^{\text {th }}$ of February 1999 . A thermal anomaly and small steam plume were detected at the summit of the volcano in short-wave thermal infrared AVHRR (Advanced Very High Resolution Radiometer) satellite imagery. This was followed by over two months of noticeable changes in the thermal character of the voleano, which erupted cataclysmically on the $19^{\text {th }}$ of April, ejecting ash to over 45 , (\%)0 fect $(13,700 \mathrm{~m})$. To date, this is the longest thermal precursory activity preceding an explosive eruption recorded by satellite imagery.

In the early weeks of activity, the thermal anomaly was only visible when the satellite passed nearly directly over the voleano, suggesting a hot source deep in the ecentral crater. The zenith angle needed to see the anomaly became larger with time, presumably as the thermal source rose within the conduit. Based on the change in zenith angles with time, and observations of the central crater's geometry, a nearly constant ascent rate of ca. $25 \mathrm{~m} /$ day for the thermal source was estimated Using this rate, the thermal source should have reached the summit sometime around the $21^{\text {st }}$ of March.

The thermal anomaly also changed in character, reaching a maxima in size around the $20^{\text {th }}$ of March. Following this, the intensity of the "hotspot" appears to have diminished, though this could be an effect of the poor weather and observing conditions at the time. On April $13^{\text {th }}$, in spite of inclement weather, the hotspot increased again in size and intensity, suggesting that molten spatter was falling just outside the central crater. On $\Lambda$ pril $17^{\text {th }}$, strombolian activity was observed by Alaska Volcano Observatory (AVO) scientists during an overflight using the FLIR instrument (Forward Looking Infrared Radiometer). The thermal anomaly again decreased, or was obscured, shortly before the climax of the cruption on April 19 ${ }^{\text {th }}$. Following this explosive phase, the thermal anomaly returned, and once exceeding an area of $20 \mathrm{~km}^{2}$, as spatter and ash were deposited near the summit.

The total thermal output was determined for the volcano and nearby regions. The thermal output for the vent region closely follows the character of the thermal anomaly, peaking at ca. $5 \times 10^{2} \mathrm{MW}$, preceding the eruption on April 19th. Thermal modeling of the whole edifice suggests that its overall heating would be low (on the order of a degree or less) and not contribute signilicantly to the total thermal output. Comparisons of the thermal output for Shishaldin, and its neighbor, Isanotski, show no significant difference, with the exception of the single pixel(s) at the Shishaldin summit crater

This type of thermal monitoring of remote volcanoes is cental in the efforts of the Alaska Volcano Observatory to provide timely warnings of volcanic eruption, and mitigate their associated hazards.

\section{CHRONOLOGY OF THE 1999 ERUPTION AND SATELLLITE IMAGES}

A: The first thermal anomaly seen at Shishaldin. The AVHRR image is overlain on a space shuttle photograph of Unimak Island (STS047-077-034). A steam plume trails $15 \mathrm{~km}$ to the south east from the volcano.

B: Two days after first sighting the anomaly is not visible in this image in spite of clear weather. The zenith angle here is too high (42.5 $5^{\circ}$, the thermal source is obscured deep in the summit crater.

C: The anomaly returns, a low zenith angle $\left(6^{\circ}\right)$ allows a clear view into the central crater

-due to increased seismicity and a persistent thermal anomaly, AVO goes to alert level yellow (26/Feb/99 2045UTC)

D: After 20 days, the thermal anomaly persists. The temperature has been rising steadily to near saturation levels and the zenith angle required to see the anomaly in the crater has been increasing (here $15^{\circ}$ ).

E: The anomaly has reached saturation for the noaa12/14 sensor. A black recovery pixel is seen near the anomaly. This is usually indicative of incandescent material on the surface. Strombolian activity may have started at this time. (zenith angle $7^{\circ}$ )

F: Following a cloudy period the anomaly appears to have increased in size. Here it must extend over $1 \mathrm{~km}$ on a side to get a pixel configuration like this. The zenith angle on this image is low $\left(5.3^{\circ}\right)$, suggesting that the geometric effects of the geo-correction for this image cannot fully explain the size increase.

G: The anomaly is stretched east-west, and reaches saturation. The zenith angle is high $\left(37^{\circ}\right)$, geometric effects help to explain the increase in size. It is likely that strombolian activity is occurring at this time. This date also corresponds to the time when the anomaly should have reached the summit, based on increasing zenith angles.

-a sudden jump in seismicity prompts AVO to go to alert level orange (7/Apr/99 1830UTC). Cloudy weather limited satellite observations. As the episode wanes, alert level is lowered to yellow (12/Apr/99 1730UTC).

$\mathrm{H}$ : The anomaly persists at saturation level (here 5 pixels, saturation at 3 , zenith angle of $38^{\circ}$ ).

-another increase in seismicity causes AVO to upgrade to alent level orange (14/Apr/99 2115UTC)

ㅇ: The anomaly seems stable, there is no sign in the thermal data of the impending plinian eruption.

-seismicity, satellite imagery and pilot reports confirm a major plinian eruption, AVO goes to alert level red (19/Apr/99 1945UTC).

J: GOES10 visible imagery of the April $19^{\text {th }}$ eruption. The plume breached the clouds at ca. 19:15 UT. Here the plume is well developed at 19:45, over 30,000 ' a.s.l.

K: Second image in the GOES sequence, the plume has reached its maximum height. The highest material heads north, then as it falls, drifts back to the south. No ash fall deposit was discovered on the north flank of this volcano following this eruption (see image $W$ ).

L: The plume stretches out in the wind field. It disappeared below the clouds at 2300 UTC. The plume was not seen again, presumably it settled out quickly.

after the first event, AVO reduces to alert level orange (20/Apr/99 1745UTC).

o. M: Post-eruption, the anomaly was absent or obscured until the $21^{\text {st }}$ of April, though well below saturation level.

-seismic tremor reaches the level of the previous eruption, AVO upgrades to alert level red (21/Apr/99 1915UTC)

$\mathrm{N}$ : The anomaly returned two days after the eruption, presumably as strombolian activity resumed at the summit.

O: Faint plumes are seen trailing from the anomalies. Here a plume stretches south-west from the summit.

-seismic levels decrease rapidly, strombolian activity continues with plumes over 30km in length. Alert level lowerd to orange (22/Apr/99 1800 UTC)

- a new explosive eruption prompts AVO to raise the alert level to red (22/Apr/99 0550UT)

P: The anomaly grows markedly in size and intensity, covering a larger area than previously seen, here over $10 \mathrm{~km}^{2}$.

Q: The anomaly reaches its largest size during this eruption (over $30 \mathrm{~km}^{2}$ ), with a short, ash rich plume extending to the south. The anomaly has been present if virtually every image since the $21^{\text {st }}$.

-with waning explosive activity, AVO has downgraded to orange (23/Apr/99 1550UTC)

R: AVO staff photographed the volcano during a fly by. Strombolian activity was pronounced, here an ash-laden plume dumps material on the southwestern flank of the volcano. Most hot material fell inside the vent.

S: FLIR (forward looking infrared radiometer) image taken on the April 23 overtlight. The warm summit glows brightly. The lower flanks would be obscured to satellite imagery by the clouds ringing the summit.

-an ash-rich plume erupted to the north on the $26^{\text {th }}$, the only plume which went to the north during this eruption

- declining seismicity prompts AVO to lower the alert level to yellow (28/Apr/99 2130UTC)

3: Clouds roll in from the north, no thermal anomaly is visible in this dusk image. Sunlight is reflected from the summit. Activity seems to have decreased sharply in the 9 days following the previous image.

U: After another 11 days, the anomaly is near saturation level. The volcano prepares for another eruption.

- a narrow ash rich plume begins erupting from the volcano, concern level raised to orange (25/May/99 1730UTC)

V: Another explosive episode creates a low altitude ash-rich plume to the south.

W: A LandSat 7 image, on the $25^{\text {th }}$ of May, courtesy of the Eros Data Center. The plume noted in the previous image is clearly visible. Ash mantles the southern fianks, lahars are seen in the snow to the north.

X: A small ash rich plume is streaming to the south-east. This plume continued for over 30 hours.

Y: The largest most ash-rich plume from the eruption, which at its peak stretched over $800 \mathrm{~km}$.

-seismicity remains low for several days, alert level lowered to yellow (1/Jun/99 1930UTC)

-3 weeks since the last explosive eruption, seismic levels approach background, alch level is lowered to green (18/Jun/99 2045UTC) 